\begin{abstract}
FRIED, ANDREW JOSEPH. Impact of Crack Sealant on Pavement Skid Resistance (Under the direction of Dr. Cassandra Castorena).

Crack sealant is a cost-effective form of preventive maintenance that is commonly used in North Carolina due to its speed and ease of application as well as its ability to extend the service life of a pavement. Crack sealing is typically ineffective at sealing pavements that experience high levels of cracking. In addition, crack sealing of highly cracked pavements, while relatively common in practice, can lead to a dangerous loss of skid resistance. This study examines the impact of crack sealant application on pavement skid resistance for six different projects within North Carolina. The Locked-Wheel Skid Tester (LWST) was used to collect the skid numbers on several projects in North Carolina with varying amounts of sealant applied. The overband crack sealant configuration was used in all projects evaluated. Photographs of the locations of LWST measurements were obtained to determine the percentage of the pavement surface area covered by crack sealant. A linear relationship between the percentage of crack sealant within the wheel path and the skid number was observed for each project. The relationship between the percentage of the wheel path covered by crack sealant and the skid number was found to depend on pavement's skid resistance prior to crack sealing. The results show that the application to pavements with extensive alligator cracking can lead to pavement conditions with unsafe skid resistance. The results of this study highlight the need for the inclusion of provisions in future crack sealant project selection specifications to prohibit unsafe conditions.
\end{abstract}


(C) Copyright 2018 by Andrew Joseph Fried

All Rights Reserved 


\title{
Impact of Crack Sealant on Pavement Skid Resistance
}

by

Andrew Joseph Fried

\author{
A thesis submitted to the Graduate Faculty of \\ North Carolina State University \\ in partial fulfillment of the \\ requirements for the degree of \\ Master of Science
}

Civil Engineering

Raleigh, North Carolina

2018

APPROVED BY:

Dr. Benjamin Underwood

Dr. Brina Montoya

Dr. Cassandra Castorena

Chair of Advisory Committee 


\section{DEDICATION}

I dedicate this thesis to my family and to my friends. Throughout my entire college career they have been there offering me constant encouragement and assistance. To my parents, Curtis and Carol, you helped me when I was struggling in school and refused to give up on me when I did not

believe in myself. Whenever I needed guidance on making a decision you were always there to offer your support regardless of what I chose. To my friends, you kept me sane and laughing throughout my entire graduate career and helped me keep going when I was unsure I could. 


\section{BIOGRAPHY}

Andrew Joseph Fried was born in Charlotte, North Carolina and grew up in Concord, North Carolina. He is the son of Curtis and Carol Fried who moved to North Carolina from Florida after deciding to start a family. He has a twin sister, Chelsea, and a younger sister Kayla who now attends North Carolina State with him. He attended Jay M. Robinson High School and participated in the North Carolina School of Science and Mathematics, where he decided that he wanted to pursue a degree in engineering and eventually decided to go to North Carolina State University for Engineering. Originally, he pursued an undergraduate degree in Nuclear Engineering before eventually switching to Civil Engineering. While pursuing an undergraduate degree he began assisting in the pavement lab while taking a materials of transportation class with Dr. Cassie Castorena. While working in undergrad he assisted with projects in both transportation materials and geotechnical engineering. This is how he became interested in transportation materials and eventually applied to graduate school for a masters in transportation materials. He finished his undergraduate degree in Civil Engineering in Fall of 2016 with a concentration in structures. His interests include transportation materials and geotechnical engineering and he took classes in both areas. His greatest joy in graduate school has been times out in the field with Dr. Haritha Malladi and Dr. Cassie Castorena at various NCDOT projects. 


\section{ACKNOWLEDGEMENTS}

I would like to thank my parents, family, friends, and colleagues for their help throughout my entire academic career. My parents encouraged me to switch majors in undergrad and were incredibly understanding of needing more time to finish my undergraduate career as a result. They encouraged me to continually better myself in school and pushed hard for me to continue my education further than I initially planned and I am so grateful that they did. To all my friends, you kept me going through graduate school when I thought it would be too much. Thank you Casey for all of the lunch and coffee breaks and for reminding me to keep going even when we are not $100 \%$ sure of where the final destination will take us. I would also like to thank Matthew Hilderbran and Anthony Prelozny at NCDOT. Your help was essential for conducting LWST tests and your assistance with the coordination of the field experiments and technical insights was invaluable for this process. I also sincerely appreciate the experience and support from and Pranav Hosangadi for his expertise and assistance with improving the MATLAB ${ }^{\circledR}$ image processing algorithm. I would like to acknowledge and thank Farhad, Michael, and Arash. You were the people who I worked the most with during my time in undergrad and were always open to teaching me the more specific details of your work as well as other projects of interest. You encouraged me to search for unique solutions to problems and to expand my knowledge around pavements. To Dr. Montoya, thank you for widening my view in the civil department by giving me the chance to work on a geotechnical project and for agreeing to sit on my committee. Dr. Underwood, thank you for agreeing to sit on my committee and for always being willing to answer questions that have come up throughout classes. Dr. Haritha Malladi deserves a special thanks because of all the work she has put into this research project. You have consistently helped me adjust to the rigors of graduate school and helped guide me in this project when I was unsure of where to go. Finally, I would like to thank the person who had the largest influence on my decision to continue pursuing education, Dr. Cassie Castorena. You encouraged me to work in the lab as an undergraduate assistant and showed me the incredible world of research and first sparked my interest in transportation materials and enabled me to continue to graduate school for research. You are one of the kindest, most patient, and intelligent people I have ever been blessed to work with and have the privilege to call my friend. Thank you for constant guidance, I will be forever grateful. 


\section{TABLE OF CONTENTS}

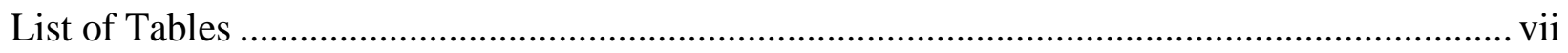

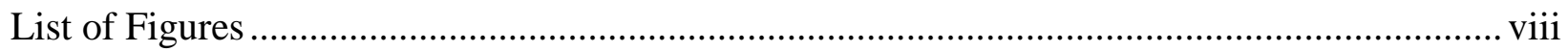

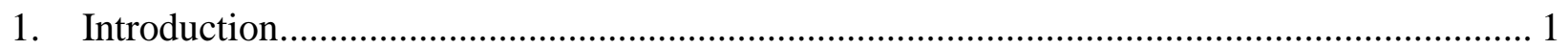

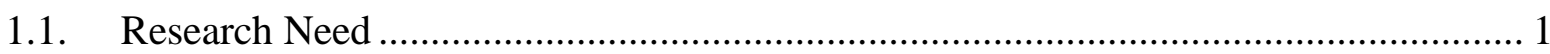

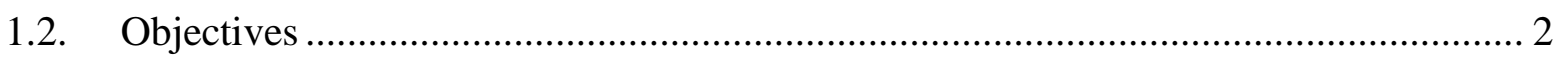

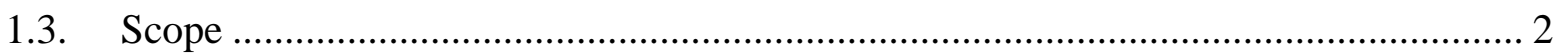

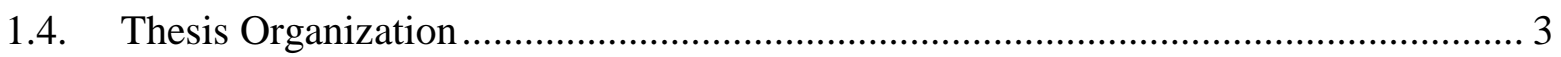

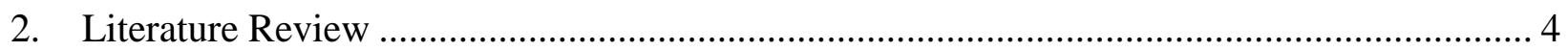

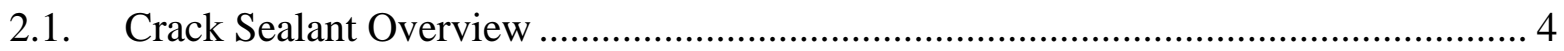

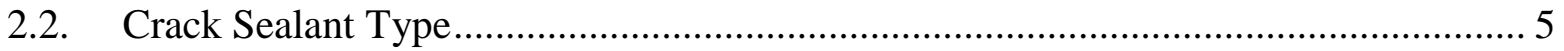

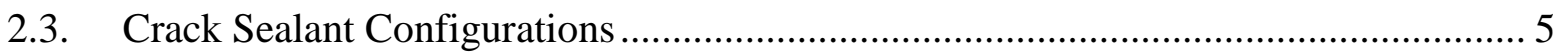

2.4. Crack sealant project selection Criteria ………....................................................... 6

2.5. Comparison of the Skid Resistance of Different Preventive Maintenance Treatments 7

2.6. Crack Sealant Quality Control.................................................................................. 8

2.7. NCDOT Specifications for Crack Sealing.................................................................. 8

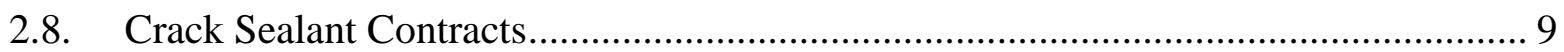

2.9. Pavement Condition Survey Practices in North Carolina ............................................. 9

2.10. Pavement Skid Resistance Measurements ............................................................. 13

2.10.1. Locked-Wheel Skid Number Thresholds ……………………...................... 16

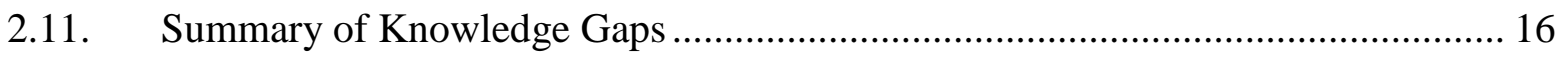

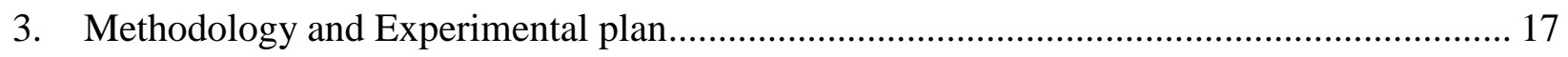

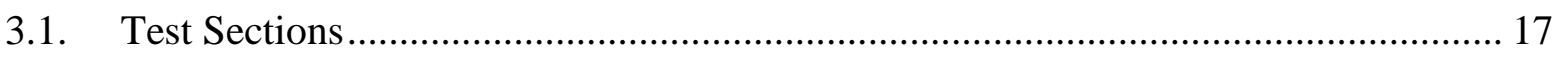

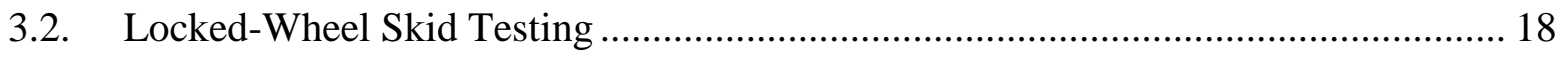

3.3. Image Acquisition and Processing …………...................................................... 19 


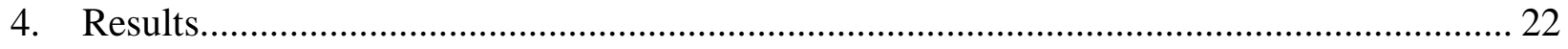

4.1. Baseline Skid Numbers ................................................................................ 22

4.2. Relationship between SN value and Percentage of Pavement surface Area Covered

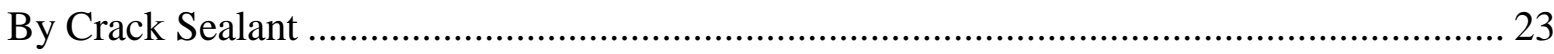

4.3. Relationship Between SN Value and Percentage of Wheel Path Covered by Crack Sealant

4.4. Establishment of Pavement Conditions Where Crack Sealing May Pose Safety

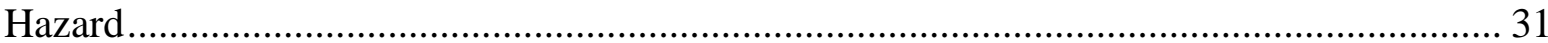

4.4.1. Allowable Percentage of Crack Sealant in Wheel Path............................... 32

4.4.2. Allowable Pavement Distress Conditions .................................................. 35

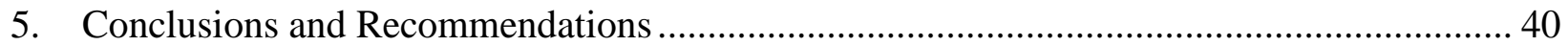

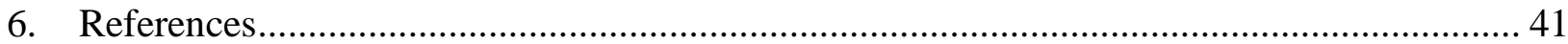

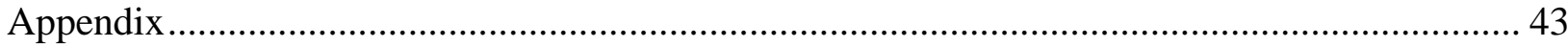

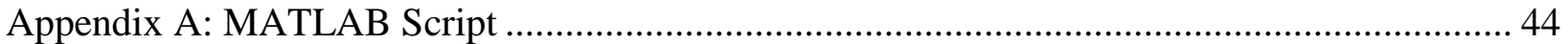




\section{LIST OF TABLES}

Table 2.1 Crack Density Classifications (Decker 2014).................................................... 7

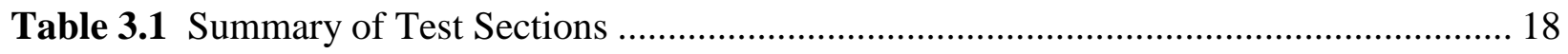

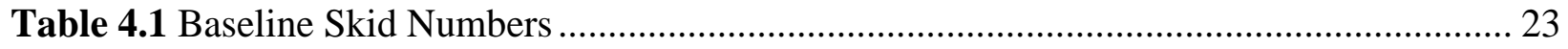

Table 4.2 Thresholds for Allowable Percentages of Crack Sealant in the Wheel Path to

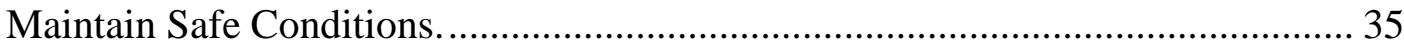

Table 4.3 Summary of Crack Sealant Coverage, SN Values, and Pre-existing Condition of

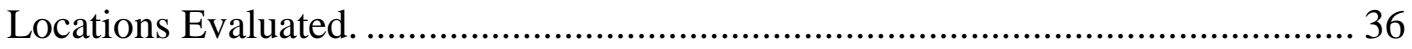

Table 4.4 Alligator Cracking Index Thresholds to Mitigate Skid Hazard for Pavements with

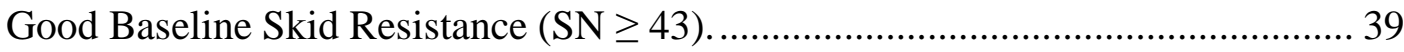




\section{LIST OF FIGURES}

Figure 1.1 Examples of excessive crack sealant application in North Carolina........................... 2

Figure 2.1 Friction number comparison of different preventive maintenance treatments

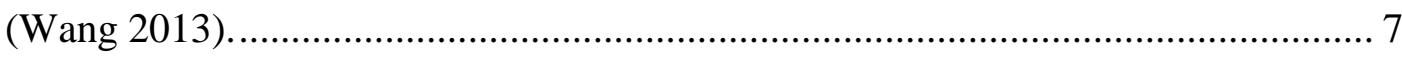

Figure 2.2 Section showing what is considered one section of pavement on 2-lane highway

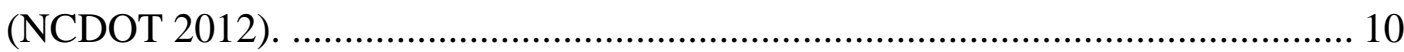

Figure 2.3 Example of severe alligator cracking (NCDOT 2012).............................................. 11

Figure 2.4 Example of severe oxidation (NCDOT 2012)....................................................... 12

Figure 2.5 Example of transverse cracking (NCDOT 2012).................................................... 13

Figure 2.6 Locked Wheel Skid Tester (McCarthy et al. 2018).................................................. 14

Figure 2.7 Grip Tester (McCarthy et al. 2018). ..................................................................... 15

Figure 2.8 Correlation between SN and GN (McCarthy et al. 2018)........................................ 15

Figure 3.1 Locked-Wheel Skid Tester. ……………............................................................ 19

Figure 3.2 Camera with GPS unit attached mounted to hood of car. ....................................... 20

Figure 3.3 Image analysis process (a) initial image, (b) perspective fixed, (c) contrast increased and wheel path focused (d) binary image................................................. 21

Figure 4.1 Relationship between LWST skid numbers and the percentage of the pavement lane covered by crack sealant for test sections in (a) Location A, (b) Location B, and (c) Location C (d) Location D, (e) Location E.

Figure 4.2 Relationship between LWST skid numbers and the percentage of the wheel path covered by crack sealant for test sections in (a) Location A, (b) Location B, (c) Location C, (d) Location D, (e) Location E and (f) Location F. 26

Figure 4.3 Relationship between LWST skid numbers and the percentage of the wheel path covered by crack sealant for all test sections.

Figure 4.4 Relationship between the change in skid numbers from the baseline and the percentage of the wheel path covered by crack sealant for test sections in (a) 
Location A, (b) Location B, and (c) Location C (d) Location D (e) Location E

(f) Location F.

Figure 4.5 Combined relationship between change in skid numbers from the baseline and the percentage of the wheel path covered by crack sealant for test sections $A, B, D$, $\mathrm{E}$, and F.

Figure 4.6 Relationship between the change in skid numbers from the baseline and the percentage of the wheel path covered by crack sealant for all test sections.

Figure 4.7 Relationship between LWST skid number and the percentage of the wheel path covered by crack sealant with 95 percent confidence intervals (dotted lines) for (a) Locations A, B, D, E, and F, and (b) Location C.

Figure 4.8 Visual representation of (a) 17 percent crack sealant within the wheel path and (b) 27 percent crack sealant coverage within the left wheel path. 35

Figure 4.9 Relationship between location minimum skid number and max crack sealant coverage in the wheel path.

Figure 4.10 Relationship between alligator cracking index and maximum percentage of wheel path covered by crack sealant. 


\section{INTRODUCTION}

\subsection{RESEARCH NEED}

Crack sealing is a cost-effective method of preventive maintenance performed on roadways to extend pavement service life. Crack sealing is applied within surface cracks. The sealant is intended to form a water-tight bond and withstand thermal expansion and contraction of the surrounding pavement, thereby preventing weakening of underlying layers and reducing the rate of pavement deterioration (FCMNRC 2003). Crack sealant application is most effective when conducted early in a pavement's life, typically within the first three to five years (FCMNRC 2003). Crack sealing should be conducted on pavements with minor to moderate cracking and good rideability because crack sealing does not improve the structural integrity of a pavement (NCDOT 2012).

While crack sealing is an effective when applied to pavements in relatively good condition, crack sealing is often applied to pavements with extensive cracking. An example is shown in Figure 1.1 (a). Pavements with extensive cracking are generally structurally compromised, making sealing ineffective. Furthermore, if the crack sealant covers too much of the pavement surface area, it can potentially degrade skid resistance. Skid resistance is critical to avoid accidents, particularly in wet weather conditions. Crack sealant may cover too much of a pavement's surface area if either excessive crack sealant is applied (e.g., overband is too wide) or the extent of cracks sealed on the pavement surface is too high. Furthermore, many agencies pay contractors for projects based on the quantity of sealant applied (NCDOT 2012, Caltrans 2003, MIDOT 2006); therefore, contractors may be indirectly incentivized to over-apply crack sealant even in locations where cracks are absent. Evidence of the application of crack sealant to a pavement area without cracks present is shown in Figure 1.1 (b). 


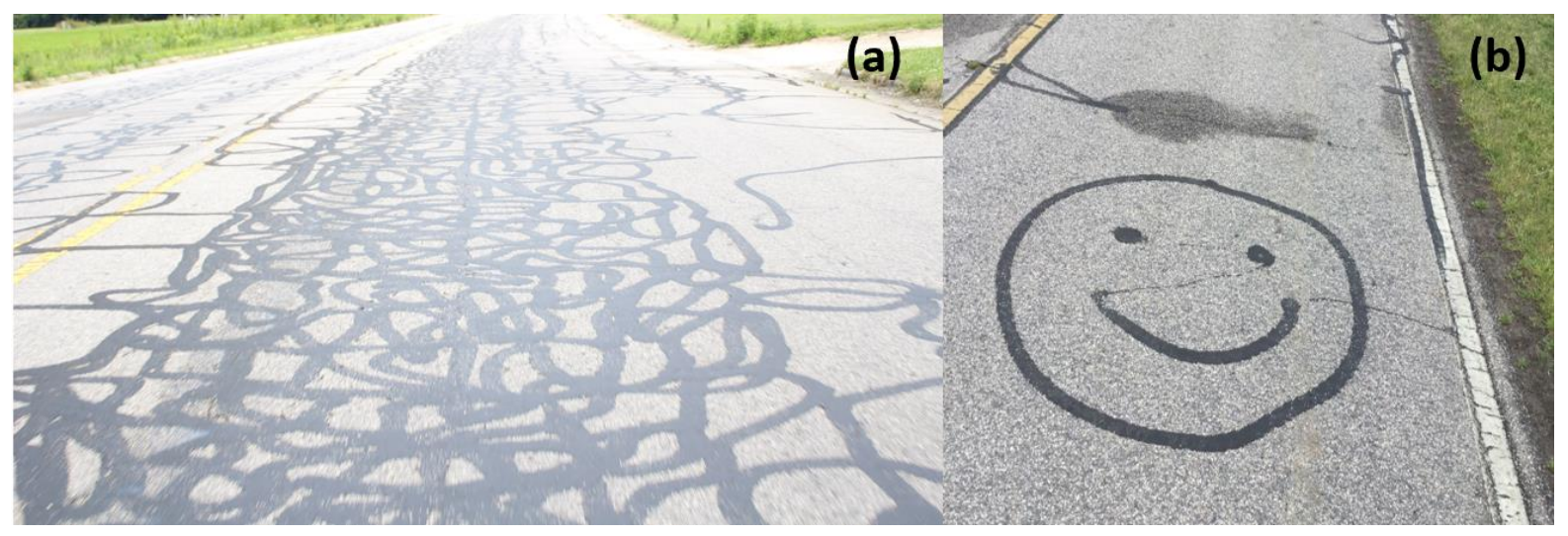

Figure 1.1 Examples of excessive crack sealant application in North Carolina. Decker (2014) conducted a national survey as part of the development of a crack sealing best practice guide to identify the criteria are used for determining if a pavement is a good candidate for crack sealing. Eighty percent of respondents indicated that three criteria are used (FCMNRC 2003) type of crack, (NCDOT 2012) percentage of cracked area on pavement, and (CALTRANS 2003) crack width. Decker (2014) did not identify any agencies with crack sealant specifications that directly prohibit skid loss. To develop such specifications, research is first needed to quantify the effect of crack sealant application on the frictional properties of pavements.

\subsection{OBJECTIVES}

The objectives of this study are to:

(1) Quantify the effect of crack sealant application on pavement skid resistance; and

(2) Identify pavement conditions where it is unsafe to apply crack sealant.

\subsection{SCOPE}

This study investigates the relationship between the amount and distribution of crack sealant application and pavement skid resistance. Locked-Wheel Skid Tester (LWST) testing was conducted on several pavement projects in North Carolina with varying amounts and patterns of crack sealant. Images of the locations of LWST testing were obtained and processed to determine the percentage of the pavement surface area covered by crack sealant. The relationship between the percentage of the wheel path covered by crack sealant and LWST results was investigated. In addition, the relationship between the percentage of wheel path covered by crack sealant and the pavement distress condition prior to sealing is examined and used to identify 
existing pavement conditions where crack sealing should be avoided because it could pose a safety hazard.

\subsection{THESIS ORGANIZATION}

This thesis is organized into five chapters. Chapter 1 presents the research needs, objectives, and scope. Chapter 2 is a review of the relevant literature. Chapter 3 presents the experimental and analysis methods employed to evaluate the impacts of crack sealant on pavement skid resistance. Chapter 4 presents the results of the field experiments, including the identification of pavement conditions where crack sealing may pose a safety hazard. Chapter 5 summarizes the conclusions and recommendations drawn from the results presented in Chapter 4. 


\section{LITERATURE REVIEW}

\subsection{CRACK SEALANT OVERVIEW}

Crack sealant is a form of preventive maintenance that is often used due to the ease and relatively undisruptive nature of its application. It is typically applied to cracks in asphalt concrete that are determined to be "working" or active cracks (Stantec Consulting 2013). A "working" crack is defined as a crack that has a width of at least $3 \mathrm{~mm}$ during the summer and expands by 15 to 100 percent during the winter (Al-Qadi et al. 2009). The primary goal of the crack sealant is to prevent the intrusion of water and other debris from infiltrating a crack; this process can help extend the pavement life-span and improve rideability for 3 to 5 years by preventing infiltration to the subgrade or base and slowing the growth of existing cracks (Hand 2000, Al-Qadi et al. 2009). When applied properly, crack sealants are expected to have a lifespan of 2 to 7 years, with reapplication recommend thereafter (Masson et al. 2004).

An INDOT study found that when comparing sealed joints to unsealed joints, there was not a significant effect on pavement distress, ride quality, bridge encroachment, material integrity, and pavement life (Hand 2000). However, it was found that crack sealing does provide benefit when applied to cracks that form in the pavement. It was found that sections that had been crack sealed exhibited less lipping and cupping at the edges of transverse cracking than unsealed sections. In addition, it was found that the extent of cracking in sealed sections was lower when compared to unsealed ones after two years of crack sealant application.

Crack sealant is applied manually using a wand attached to a heated trailer that melts the material. The crack is routed prior to sealing if it is determined by visual inspection that the dirt and debris could cause the sealant to not properly stick to the wall of the crack. All cracks are cleaned with a hot air lance that removes debris before application. Once the hot air lance has been used to clear debris, the sealant is applied via a heated wand. The sealant is spread to be level with the surrounding pavement surface with a squeegee and allowed to cool to the ambient pavement temperature. Crack sealant is typically applied during the late spring due to the requirement of applying when pavement temperature is between its lowest and highest extremes to reduce risk of the sealant itself cracking (Gnatenko et al. 2016). 
Not all types of cracking are ideal for crack sealing. A pavement that exhibits alligator cracking, poor sub-base drainage, structural damage, or cracks with widths that exceed $20 \mathrm{~mm}$, is not an ideal good candidate for sealing (Stantec Consulting 2013). Identifying these routes early and marking them as unfit for sealing could help reduce the amount of over-sealing that sometimes occurs on lower volume roadways.

\subsection{CRACK SEALANT TYPE}

There are two main types of crack sealant application methods, hot and cold applied. Hot application is more commonly used due to a myriad of benefits. The major benefits are the ease of application, the amount of DOTs that have equipment for cold application is limited, the speed at which the sealant is applied, and overall performance. This was backed up by research done by a research team in Canada led by Yildirim (2007). Most crack sealants used in North Carolina are hot pour sealants. The benefits of cold pour sealants include the reduced temperatures at which they are applied, amount of time spent on construction, and their ability to fill cracks more easily than hot-poured sealants (Yildirim 2007).

\subsection{CRACK SEALANT CONFIGURATIONS}

There are several types of crack sealant configurations that are used in practice, with the most common including recessed fill, flush fill, and overband (Decker 2014). The type of crack sealant application examined for the purpose of this project was overband due to its prevalence in North Carolina. The overband configuration is favored by many DOTs due to the speed and ease of application (Chehovits and Maning 1984). Overband sealant application involves heating the crack sealant to the desired temperature and applying directly to the crack using a heated wand. After application, the excess sealant is squeegeed so that the sealant is level with the road surface. This entire process is more efficient and rapid compared to the recessed fill and flush fill configurations. However, the disadvantages of the overband configuration include appearance, rideability, and increased exposure to traffic and environmental factors due to the increase in surface area (Chehovits and Manning 1984). Due to the smooth texture of the overbanded sealant compared to pavement, there is a concern this configuration can lead to skid loss if a significant amount of pavement is covered in sealant. Because of these concerns, the overband configuration is most often suggested only for low volume roads (Caltrans 2003). 
The flush fill sealant configuration differs from the overband configuration in terms of appearance and application site. Flush filled cracks are filled only to the surface of the crack and not over; therefore, the flush filled configuration is less susceptible to tensile strains, is typically more aesthetically appealing than overband, and can be used on higher trafficked routes (Caltrans 2003). However, it is more difficult and time consuming to apply and does not adequately seal cracks with edge deterioration (Caltrans 2003).

The recessed fill sealant configuration differs from the flush fill with respect to the height to which the crack is filled. Recessed filled cracks are sealed to a height slightly below the surface of the crack. This is done to prevent the sealant from being tracked by vehicles and being damaged by snow plows (Caltrans 2003). The primary disadvantage of the recessed fill configuration is the difficulty of its application. In order to be properly applied, cracks must first be cleaned and then routed (Caltrans 2003).

\subsection{CRACK SEALANT PROJECT SELECTION CRITERIA}

Candidate pavements for crack sealing are identified based on crack width, crack depth, crack density, and crack type and orientation based on a national survey distributed to state DOTs (Truschke et al. 2013). In a similar survey conducted by Decker (2014), it was found that 80 percent of respondents used three criteria for determining the suitability of a pavement for sealing: type of crack, percentage of surface covered by cracks, and crack width (Decker 2014).

Cracks that are found to be appropriate for sealing can typically be classified as longitudinal, transverse, or block. Sealing is generally not recommended for pavements that exceed low to moderate cracking densities (Decker 2014). Low to moderate cracking densities are more clearly defined below by Table 2.1. Another example of rejection for sealing include roadways where alligator cracking exceeds 25 percent of the pavement surface being covered in cracks (Decker 2014). Currently, no agencies specify project selection specifically to mitigate safety hazards associated with crack sealant application diminishing skid resistance. 
Table 2.1 Crack Density Classifications (Decker 2014).

\begin{tabular}{|l|l|}
\hline $\begin{array}{l}\text { Linear Crack Length } \\
\text { per } 100 \mathrm{~m}(328 \mathrm{ft}) \text { pavement section }\end{array}$ & Density Definition \\
\hline$<10 \mathrm{~m}(33 \mathrm{ft})$ & Low \\
\hline $10 \mathrm{~m}(33 \mathrm{ft})$ to $135 \mathrm{~m}(443 \mathrm{ft})$ & Moderate \\
\hline$>135 \mathrm{~m}(443 \mathrm{ft})$ & High \\
\hline
\end{tabular}

\subsection{COMPARISON OF THE SKID RESISTANCE OF DIFFERENT PREVENTIVE MAINTENANCE TREATMENTS}

The underlying hypothesis of this study is that crack sealant application can lead to a reduction in pavement surface friction. A research team at The State University of New Jersey examined the skid resistance of four different types of preservation treatments: thin overlay, slurry seal, crack seal, and chip seal (Wang 2013). Cracking sealed sections had the lowest friction of all treatment types except for thin overlays. The authors rated the performance of the pavements on a scale of one to five with one exhibiting the worst. Ranking performance of pavement preservation techniques in four different climates and averaging the different types of sections, crack sealed sections were found to be the least effective treatment option (Wang 2013).

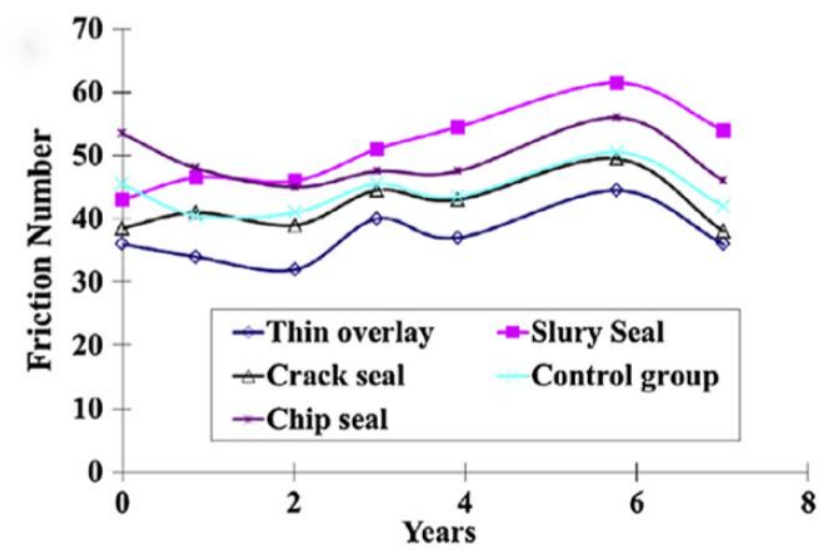

Figure 2.1 Friction number comparison of different preventive maintenance treatments (Wang 2013). 


\subsection{CRACK SEALANT QUALITY CONTROL}

The primary issues associated with over application of crack sealant include poor finish, incorrect usage of finishing tools, sealant applied at lower temperature, breakdown of sealant due to excess heating, and hot environments (Caltrans 2003). Many of these issues can be reduced with proper quality control during the installation process. Examples of quality control measures are inspection of the crack, sealant sampling and testing, properly calibrating equipment, and inspecting the equipment (Decker 2014). Inspection of the equipment is an important step in quality control and should be performed according to the manufacturer's recommendation (Decker 2014). However, the most important aspect of quality control is inspecting the application of sealant. Checking cracks to ensure that they are properly cleaned/prepared for application helps ensure that sealant with adhere to the pavement and do its job effectively (Decker 2014).

\subsection{NCDOT SPECIFICATIONS FOR CRACK SEALING}

The NCDOT specifications for crack sealing are given in the NCDOT 2012 Standard Specifications document in Section 657. The specifications dictate that existing longitudinal and transverse pavement cracks should be sealed with hot applied joint sealer (NCDOT 2012). Edge cracks do not require sealing according to the NCDOT specification.

The specifications require cleaning of cracks and joints using a hot compressed air lance to remove any dirt, vegetation, dampness, and loose materials prior to sealing. The hot air lance must be used immediately prior to sealing the pavement to ensure the crack is dry and warm (NCDOT 2012). The sealant is heated and applied according to the manufacturer's recommendations. A portable melting kettle is used for heating the material and the material must be constantly agitated in order to maintain a uniform temperature (NCDOT 2012). Material should be heated between $200^{\circ} \mathrm{F}$ and $600^{\circ} \mathrm{F}$. It is crucial to monitor the temperature of the sealant because overheating is not allowed according to NCDOT's specification. The sealant should be spread after application using a pressure screed shoe to completely fill the crack, leaving a 2 in overband. The sealant should be immediately squeegeed in order to limit the height of the sealant and limit the impact on rideability. All sealed cracks should have a minimum of $1 / 8$ inch depth of sealant installed (NCDOT 2012). 
There are several restrictions that are also accounted for in the NCDOT specification. Excessive overbanding or wasting of sealant materials is not allowed. However, it is unclear what is considered excessive and how this is monitored. If the pavement temperature is below $32^{\circ} \mathrm{F}$, the pavement cannot be sealed. After the sealant has been applied and excess sealant is removed, traffic is not allowed on the roadway until it is approved by the engineer. When it is approved by the engineer, sand, toilet paper, or another approved material can be placed on the sealant to help prevent tracking (NCDOT 2012).

\subsection{CRACK SEALANT CONTRACTS}

Crack sealant contract payment terms often incentivize the over application of the sealant. In North Carolina, payment for crack sealant project is made on the basis of linear meter of sealant applied or by pound of sealant applied (NCDOT 2012). Canada pays their contractors by the linear meter of sealant applied (NGSMI 2003). These types of payments could lead to an incentive to seal excessively and seal the pavement where cracks are not in actuality forming. In Colorado, projects are bid by estimating the number of miles that will be sealed and determining the cost based on the estimated number of gallons of emulsion that will be used (Truschke et al. 2014).

\subsection{PAVEMENT CONDITION SURVEY PRACTICES IN NORTH CAROLINA}

The goal of this study is to relate pavement skid resistance changes from crack sealant application to existing roadway conditions so that the NCDOT can develop specifications to preclude the application of crack sealant to roadways where it will pose a safety hazard.

Therefore, the NCDOT procedures for conducting pavement distress surveys and defining the condition of the pavement were reviewed. The NCDOT assigns a Pavement Condition Rating (PCR), ranging from 0 to 100 that determines the overall condition of a roadway. On this scale, a rating of 0 is corresponds to a highly damaged road and 100 corresponds to a road in perfect condition. Roadways in a severely deteriorated condition indicate that the operating speed of the road cannot be maintained safely (NCDOT 2016).

As of 2012, NCDOT conduct automated distress surveys on primary roadways and windshield surveys on secondary roadways. In manual, windshield surveys, NCDOT Pavement Condition Surveys are completed for each section of roadway for a given route. The division of a roadway 
into sections depends on the type of roadway being analyzed. Most routes examined in this study would fall under the description of a secondary, two lane highway, as shown in Figure 2.2. The evaluation of these roadways by NCDOT typically only had one section per route examined, while a few longer routes did have multiple sections.

For two-lane roads, the rater will evaluate both lanes. Each lane is $50 \%$ of the total section.

\section{Lane Highway}

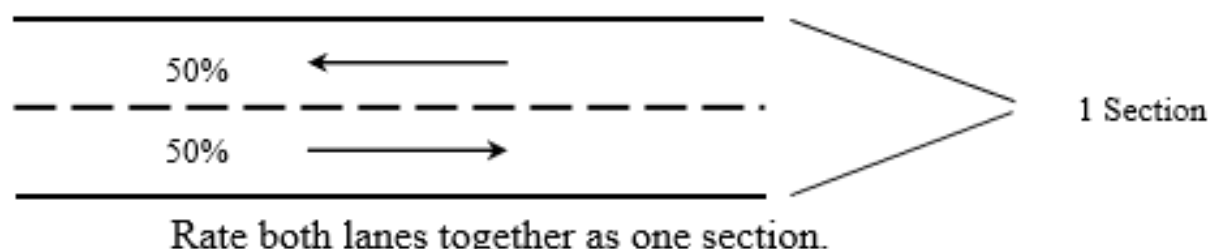

Figure 2.2 Section showing what is considered one section of pavement on 2-lane highway

(NCDOT 2012).

The NCDOT pavement distress surveys quantify the extent and severity of many distresses along a section. A section is defined as a route that is of similar condition/pavement material and is less than two miles in length (NCDOT 2016). The distresses that are anticipated to impact the effect of crack sealant on pavement skid resistance include: alligator cracking, transverse cracking, and oxidation. Alligator cracking and transverse cracking affect the extent of sealant that will be required to seal cracks in the roadway whereas raveling and oxidation have significant impacts on the existing roadway frictional characteristics. In cases of severe alligator cracking, it is likely that crack sealant will be overapplied to fill all cracks, posing a potential loss in skid resistance. Furthermore, alligator cracks exist in the wheel path where skid resistance is most critical. Oxidation often impacts the surface characteristics, including raveling. Raveling is anticipated to impact skid resistance; however, the NCDOT only quantifies raveling on slurry seals and chip seals.

The NCDOT Pavement Condition Survey Manual (PCS) assigns rankings for alligator cracking are Light, Moderate, and Severe (NCDOT 2016). Light cracking is classified as longitudinal disconnected hairline cracks about 1/8 inch wide that run parallel to each other on the pavement. 
Moderate cracking is when longitudinal cracks in the wheel path connect together and form cracks that are about 1/4 inch wide. Severe cracking, shown below by Figure 2.3, is when the cracks have advanced to the point where pieces of pavement appear to be loose and the cracks are about $3 / 8$ to $1 / 2$ inch wide (NCDOT 2016). In NCDOT PCS Manual, the alligator cracking also includes longitudinal and edge cracking.

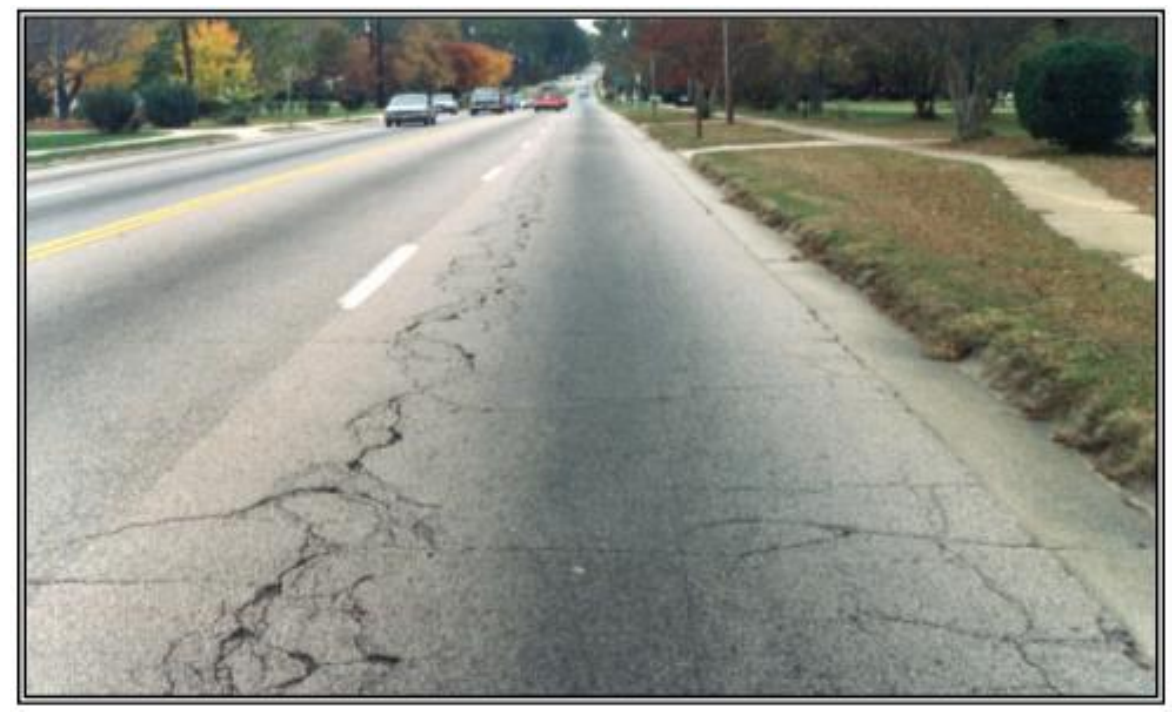

Figure 2.3 Example of severe alligator cracking (NCDOT 2012).

The alligator cracking index is calculated and reported by the NCDOT by using the percentage of area of roadway covered by none, low, medium, and high severities of alligator cracking. An analysis of the NCDOT distress survey data that compared the reported alligator cracking index to the reported values for low, medium, and high severity cracking indicates that it is calculated using Equation 2-1.

$$
A C_{\text {Index }}=100-(0.5 \cdot \% L O W+\% M E D+4 \cdot \% H I)
$$

Where \%LOW refers to the percentage of the total area of the lane that is low severity. \%MED is the percent of the total area that is medium severity. $\% \mathrm{HI}$ is the percent of the total area that is high severity. In addition, \%NONE refers to the percentage of the total area that exhibits no alligator cracking. The summation of \%NONE, \%LOW, \%MED, and \%HI must equal 100 (NCDOT 2016). 
The oxidation rating is an indication if there is oxidation on the route being inspected. Oxidation occurs when a pavement hardens from oxidative aging caused by exposed to certain environmental factors. The NCDOT has two ratings for oxidation; none and severe (NCDOT 2016). Oxidation is determined by visually analyzing the entire surface and determining if the pavement is showing significant signs of discoloration. The oxidation index is reported with a value of 100 , indicating no signs of oxidation, or a value of 0 , indicated severe oxidation. An example of an oxidation index of 0 is given in Figure 2.4.

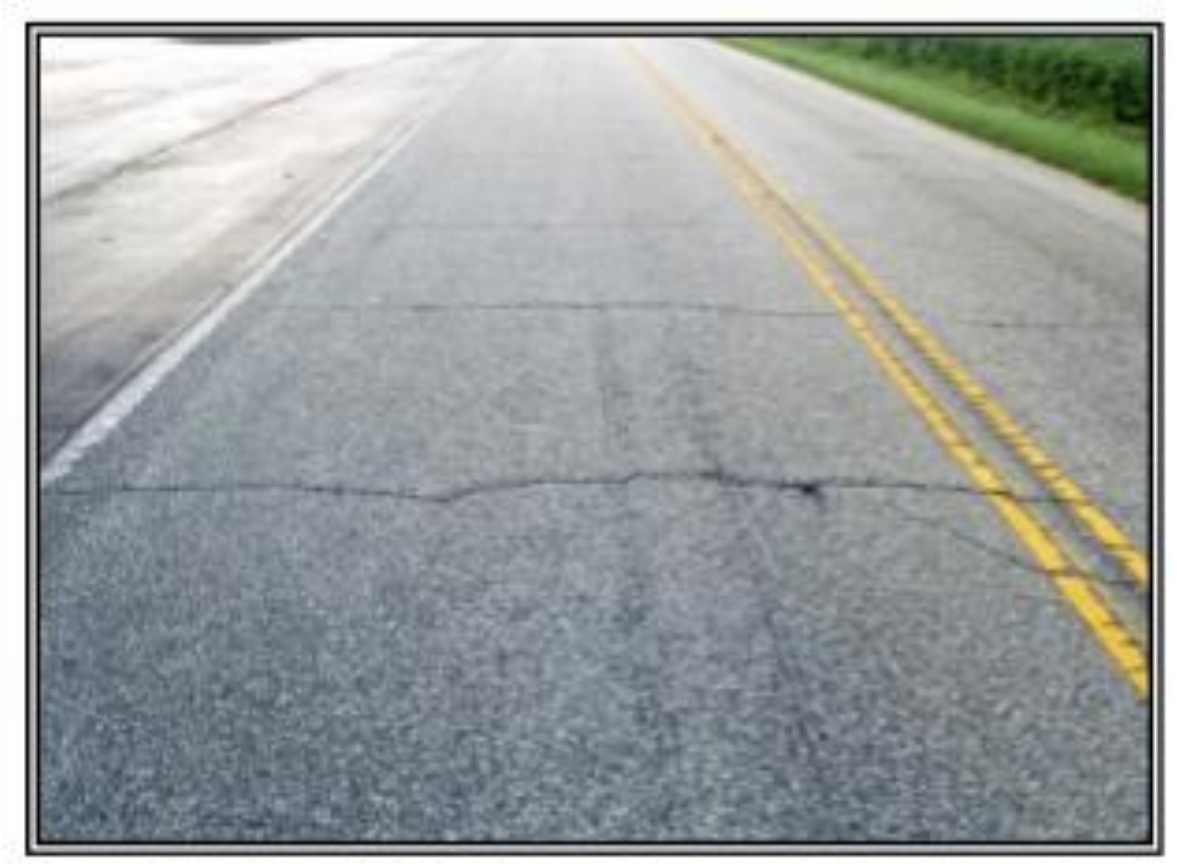

Figure 2.4 Example of severe oxidation (NCDOT 2012).

The transverse cracking index refers to the amount of cracking that occurs perpendicular to a roadway. These cracks are typically greater than $1 / 2$ inch wide and typically cross both lanes of traffic (NCDOT 2016). Transverse cracking can be caused by thermal stresses and reflective cracking. Reflective cracking occurs when a crack reflects to the surface of the new asphalt layer from the underlying pavement. A transverse cracking index is determined by the width of the crack and the frequency of the cracks; however, the specific formula used to calculate the index is not reported. If cracks are less than 1/4 inch wide and occur less frequently than every 10 to 20 feet, the transverse cracking is classified as light. Moderate cracking is classified as cracks with 
width between $1 / 4$ to $1 / 2$ inch that are spaced 5 to 20 feet apart (NCDOT 2016). Severe transverse cracks have a width greater than 1/2 inch and occur 1 to 2 feet apart (NCDOT 2016).

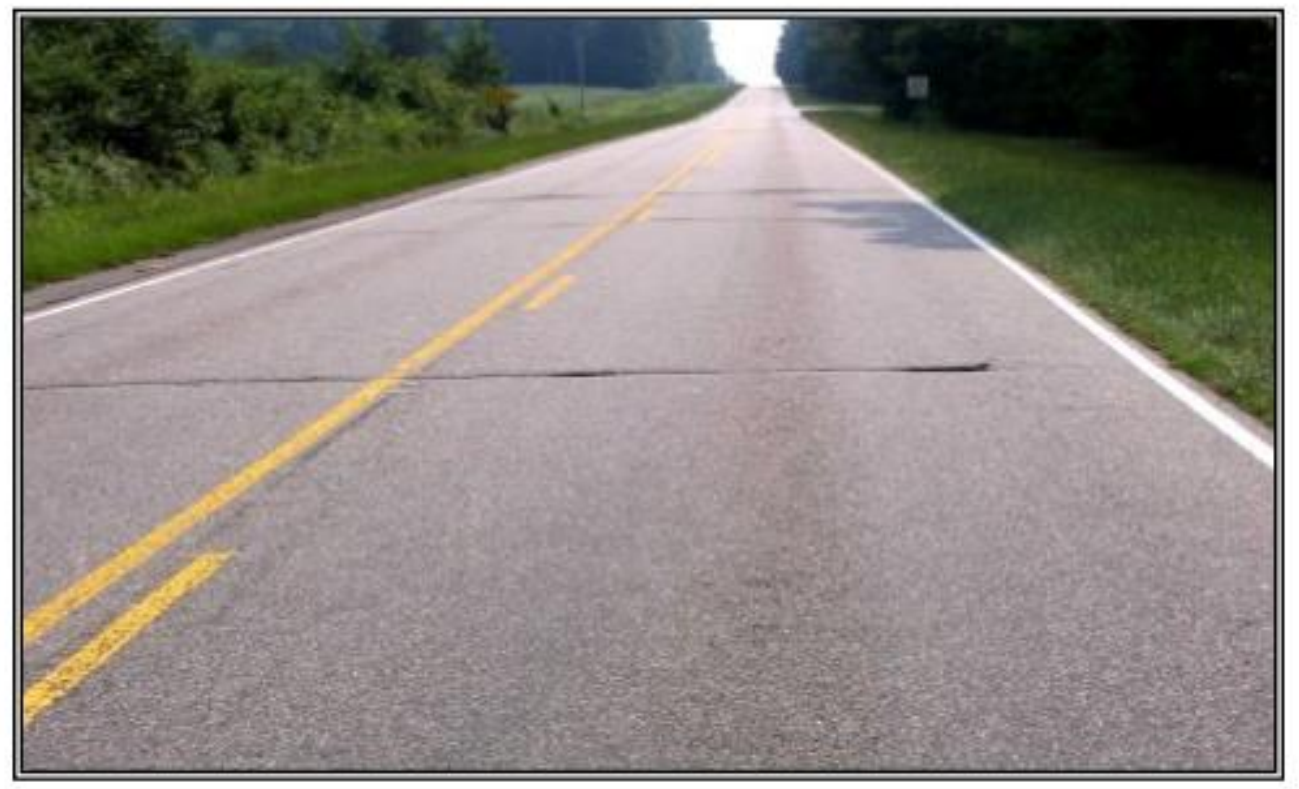

Figure 2.5 Example of transverse cracking (NCDOT 2012).

\subsection{PAVEMENT SKID RESISTANCE MEASUREMENTS}

Two common techniques used in practice to measure pavement skid resistance include: the Locked-Wheel Skid Tester (LWST) and the Continuous Friction Tester (CFT). Additional techniques exist but are not under consideration by the NCDOT at this time and thus, are omitted from this review. McCarthy et al. (2018) examined the main differences between the different types of friction testers available for DOTs. The two that are most related to the current crack sealant project are the Grip Tester, (a type of CFT) and the LWST (standard smooth tire) due to how NCDOT measures friction values.

The LWST (ASTM E274) measures the pavement friction at a set interval by periodically locking a tire attached to a trailer, as shown in Figure 2.6. This wheel is locked when the vehicle reaches a consistent speed of $40 \mathrm{mph}$. Both smooth and ribbed tires are available. The smooth tire is sensitive to changes in mean profile depth (MPD) of the pavement which makes it preferable to the ribbed tire version of the LWST. The primary benefit of using a LWST is that it takes the measurement in the actual wheel path of traffic. The recorded value is reported as a 
Skid Number (SN) and calculated by the formula shown below in Equation

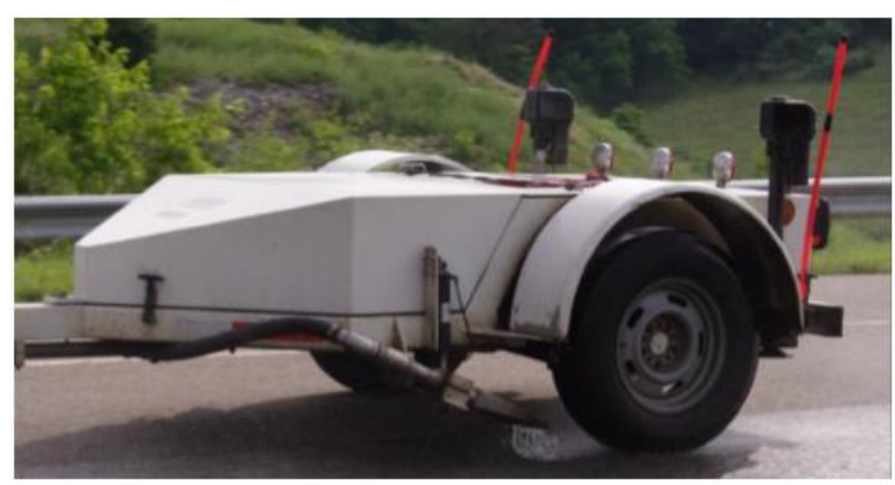

Figure 2.6 Locked Wheel Skid Tester (McCarthy et al. 2018).

$\mathrm{SN}=(\mathrm{F} / \mathrm{W}) \times 100$

where SN = Skid Number, F = Tractive Force (i.e., the horizontal force applied to the test tire at the tire-pavement contact patch), lbf (or N), and $\mathrm{W}=$ dynamic vertical load on test wheel, lbf (or $\mathrm{N})$. The method of measurement is the same for the LWST with a ribbed tire; however, it is less sensitive to the changes of MPD in a pavement's surface.

The CFT method is a popular method of measuring friction on runways and airfields. The CFT is typically measured using a grip tester. Fundamentally, it works the same way as the LWST by locking up a wheel but the increments at which it locks up are occurring at such short intervals so it is considered as continuous. A grip tester, shown below in Figure 2.7, measures a value that is reported as a GN (Grip Number), which is a measure on the longitudinal force required to slow the middle tire of the grip tester. For most grip testing, the tires used are smooth instead of ribbed, which makes them more reliable for measuring the effect of MPD on a pavement's skid resistance. A GN value is the metric used to measure the friction of the pavement surface and is determined by calculating the amount of friction necessary to bring a wheel to 15 percent of the speed of the trailer. By not fully locking the wheel up, the test is able to record values at short intervals such as every 3 feet. The CFT can be operated at a range of speeds. 


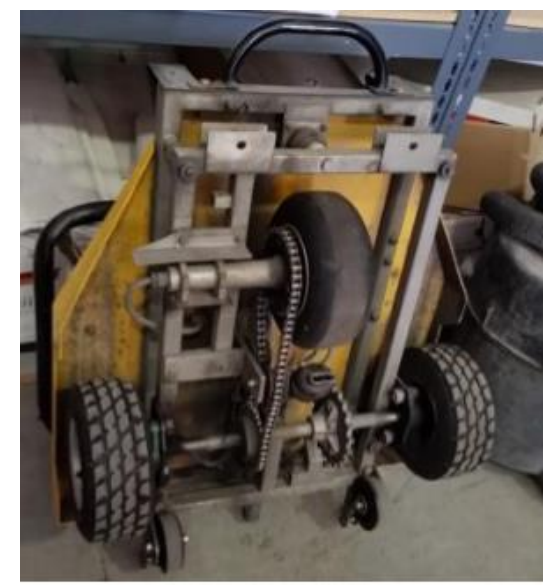

Figure 2.7 Grip Tester (McCarthy et al. 2018).

The main differences between the LWST and a CFT are test interval length, speed at which friction value is recorded, sensitivity to MPD, how friction value is calculated, and the location where the wheel records the friction value. The LWST has a test tire that records values that are in the actual wheel path of the vehicle while the grip tester records values in the center or the travel lane. The GN value is also measured without fully locking up the test tire while the LWST locks the tire entirely. McCarthy et al. (2018) correlated LWST and CFT results (both with smooth tires) and found only a weak relationship with $\mathrm{R}^{2}$ of 0.44 as shown in Figure 2.8. Due to the significant differences in equipment, measurement, and lack of overall correlation it is unlikely that continuous friction tester data can be combined to that found with the LWST.

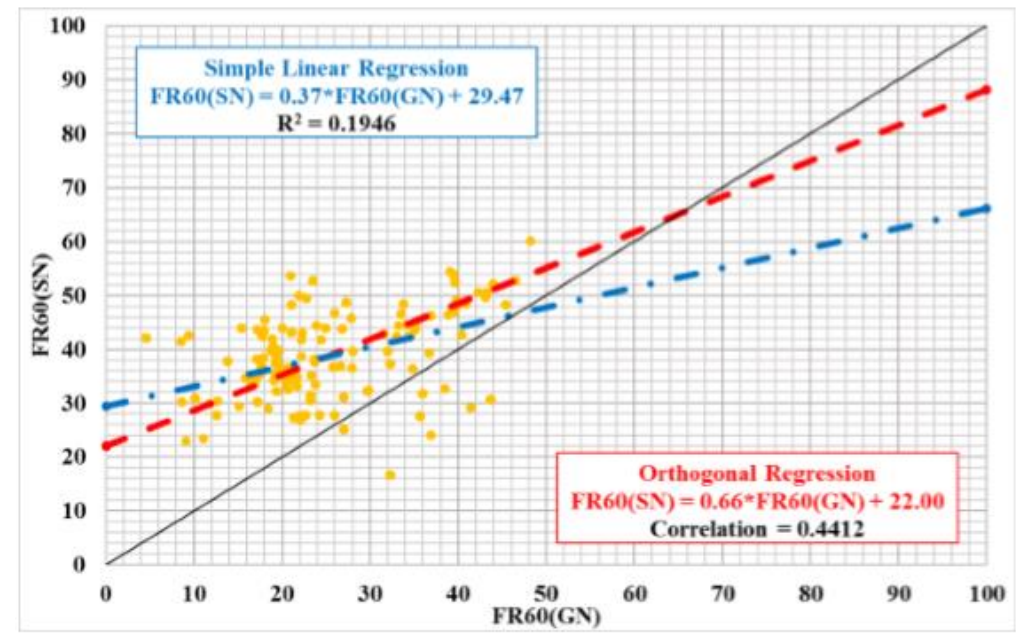

Figure 2.8 Correlation between SN and GN (McCarthy et al. 2018). 


\subsubsection{LOCKED-WHEEL SKID NUMBER THRESHOLDS}

$\mathrm{SN}$ values are often used as indicators of roadway safety. Based on a nationwide survey of LWST use performed by Jayawickrama et al. (1996), it was determined an SN of 30 is the minimum acceptable value for low-volume roads and that a minimum SN of 35 is required for high-volume roads. Pavements that have skid values of between 31 and 34 are typically monitored closely by state agencies so that preventive maintenance can be performed and increase the SN value to maintain safe conditions (Jayawickrama et al. 1996).

If a roadway has an $\mathrm{SN}$ value that falls below 30, many DOTs would then consider corrective action due to likelihood of a skid-related accident occurring. The widespread use of these thresholds has to do with their values relating directly to the ASTM E274 LWST, which is used widely across the United States. Some states such as Maryland, Minnesota, and Pennsylvania have higher thresholds such as 40 as a cutoff for determining unsafe conditions (Jayawickrama et al. 1996). However, for the purposes of this study, NCDOT values for safety thresholds were used, which are consistent with thresholds established by Jayawickrama et al. (1996).

\subsection{SUMMARY OF KNOWLEDGE GAPS}

Key findings in this literature review established the tools, pavement thresholds, methods, calculations, and selection of projects for this study. The literature presented demonstrates that the selection of projects for crack sealing does not consider the impact that the crack sealant will have on skid resistance. Many factors that can affect crack sealant application were presented (e.g., existing pavement condition, configuration, sealant type, etc.). Therefore, the present study is critical to inform future specification development to prevent the over application of crack sealant in cases where it could pose a safety hazard. The existing pavement condition and type of crack sealant configuration potentially play a significant role in whether pavements are being unsafely sealed. 


\section{METHODOLOGY AND EXPERIMENTAL PLAN}

\subsection{TEST SECTIONS}

Six pavement sections in North Carolina were analyzed in this study. Each section exhibited significant variability in the coverage by crack sealant along its length; this allowed for evaluating the relationship between the percentage of the pavement covered by crack sealant and pavement skid resistance over sections with consistent existing pavement surface characteristics. A summary of the six test sections is given in Table 3.1. Location $\mathrm{C}$ includes two subsections, $\mathrm{C} 1$ and $\mathrm{C} 2$ because the route included two segments for which pavement distress condition survey data was obtained and recorded. For the other locations, a single record of pavement distress condition survey data was available for the entire route length. The pavement condition rating, alligator cracking index, transverse cracking index, and oxidation rating values reported in Table 3.1 correspond to the pavement condition before sealing. It should be noted that all of the sections evaluated were secondary roadways and thus, manual windshield surveys were used to obtain these measurements. All test sections were cracked sealed but many exhibited evidence of relatively extensive cracking. While the extent of alligator cracking is shown to vary among the locations, it can be seen that the transverse cracking index of all sections except one were 80 . It should also be noted that both longitudinal and alligator cracks are grouped together under alligator cracking within North Carolina Department of Transportation (NCDOT) distress surveys (NCDOT 2016). In addition, except for Location C, the test locations did not exhibit visual evidence of oxidation; an oxidation rating of zero indicates that oxidation was not observed and a rating of 100 indicates a severely oxidized pavement. The crack sealant configuration used in all locations was the overband, which is prevalent in North Carolina. 
Table 3.1 Summary of Test Sections

\begin{tabular}{|c|c|c|c|c|c|c|c|}
\hline Location & $\mathrm{A}$ & $\mathrm{B}$ & $\mathrm{C} 1$ & $\mathrm{C} 2$ & $\mathrm{D}$ & $\mathrm{E}$ & $\mathrm{F}$ \\
\hline Length mi [km] & $\begin{array}{c}2.0 \\
{[3.2]}\end{array}$ & $\begin{array}{c}1.1 \\
{[1.8]}\end{array}$ & $\begin{array}{c}2.2 \\
{[3.5]}\end{array}$ & $\begin{array}{c}1.9 \\
{[3.0]}\end{array}$ & $\begin{array}{c}1.4 \\
{[2.2]}\end{array}$ & $\begin{array}{c}1.0 \\
{[1.6]}\end{array}$ & $\begin{array}{c}1.5 \\
{[2.4]}\end{array}$ \\
\hline Number of Test Sites* & $\begin{array}{c}16 \\
(20)\end{array}$ & $\begin{array}{c}11 \\
(11)\end{array}$ & $\begin{array}{c}10 \\
(11)\end{array}$ & $\begin{array}{c}10 \\
(14)\end{array}$ & $\begin{array}{c}7 \\
(14)\end{array}$ & $\begin{array}{c}4 \\
(8)\end{array}$ & $\begin{array}{c}8 \\
(15)\end{array}$ \\
\hline Test Interval mi [km] & $\begin{array}{c}0.1 \\
{[168]}\end{array}$ & $\begin{array}{c}0.1 \\
{[163]}\end{array}$ & $\begin{array}{c}0.2 \\
{[322]}\end{array}$ & $\begin{array}{c}0.2 \\
{[322]}\end{array}$ & $\begin{array}{c}0.1 \\
{[163]}\end{array}$ & $\begin{array}{c}0.1 \\
{[163]}\end{array}$ & $\begin{array}{c}0.1 \\
{[163]}\end{array}$ \\
\hline $\begin{array}{c}\text { NCDOT Pavement } \\
\text { Condition Rating } \\
\text { (NCDOT 2016) }\end{array}$ & 80.10 & 76.80 & 71.19 & 76.44 & 63.60 & 69.30 & 65.60 \\
\hline $\begin{array}{c}\text { NDCOT AC Alligator } \\
\text { Index (NCDOT 2016) }\end{array}$ & 86.67 & 82.22 & 73.40 & 77.50 & 64.44 & 72.63 & 76.56 \\
\hline $\begin{array}{c}\text { Oxidation Rating } \\
\text { (NCDOT 2016) }\end{array}$ & 0 & 0 & 100 & 100 & 0 & 0 & 0 \\
\hline $\begin{array}{c}\text { Transverse Cracking } \\
\text { Index (NCDOT 2016) }\end{array}$ & 80 & 80 & 80 & 80 & 80 & 80 & 100 \\
\hline
\end{tabular}

*First number corresponds to the number of test site results deemed acceptable, number in parentheses corresponds to the total number of test sites.

\subsection{LOCKED-WHEEL SKID TESTING}

The LWST was used to measure the skid resistance of pavements with varying amounts of crack in the wheel path in accordance with ASTM E274 (2011). The LWST used consists of a trailer with a test wheel, water supply and dispensing system, and instrumentation system to measure frictional force. The trailer is towed by a vehicle traveling at $40 \mathrm{mph}(64 \mathrm{~km} / \mathrm{h})$. Once up to speed the LWST sprays water 12 to 18 in in front of the test tire as well as 1 in to the left and right of the tire to ensure a wetted surface for the tire. The trailer's test wheel is positioned in the left wheel path and is locked and dragged over wetted sections of pavement in order to measure the steady-state friction. The LWST used in this study is a smooth, single tire and is shown in Figure 3.1. 


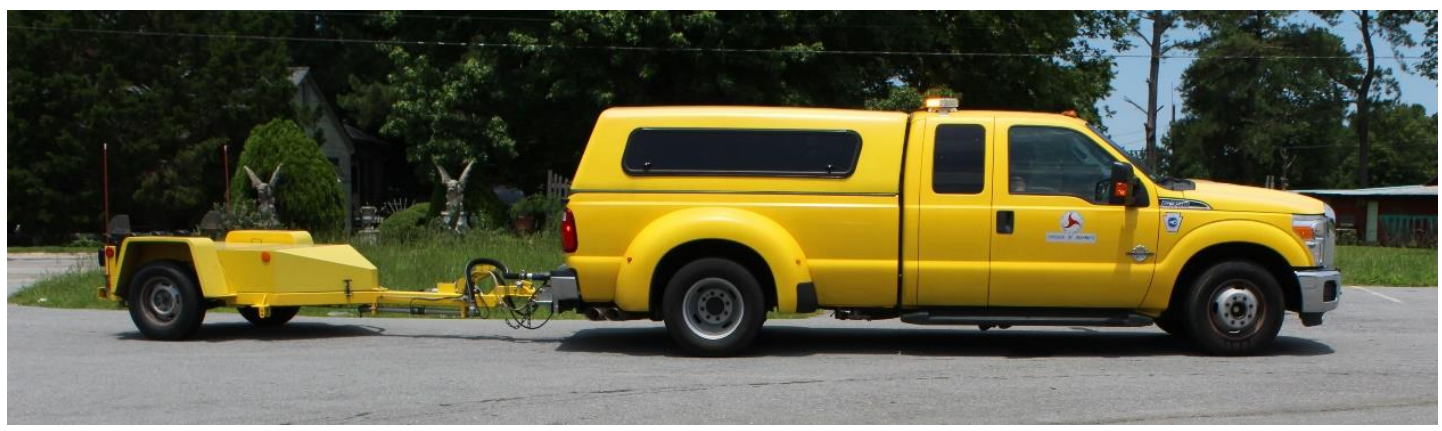

Figure 3.1 Locked-Wheel Skid Tester.

The LWST was used to determine the skid number (SN) at each site of testing. The SN number is recorded as the average value for the duration of each skid test and is calculated by using Equation (2-2). LWST tests were conducted at constant intervals with different intervals depending on the overall length of the section. Longer sections included measurements every 0.2 miles $(322 \mathrm{~m})$ while shorter sections took measurements around 550 feet $(168 \mathrm{~m})$. SN values were removed from the data set if the speed was not $40 \mathrm{mph}(64 \mathrm{~km} / \mathrm{h})$ or if the photo showed significant amount of wandering from the wheel path.

\subsection{IMAGE ACQUISITION AND PROCESSING}

A vehicle with a camera mounted to its hood closely followed the LWST to obtain images of the pavement sections over which $\mathrm{SN}$ values were measured to allow for comparing skid resistance to crack sealant coverage. The camera mounted to the vehicle is shown in Figure 3.2. The location of each LWST test was easily identified by the watermark left on the pavement. Two photographs were taken for each skid mark. The camera contained a Global Positioning System (GPS) unit, which allowed for reconciling the images with the corresponding LWST result. A handheld GPS unit was also used to record the location of each photograph in case of failure of the camera's GPS unit. 

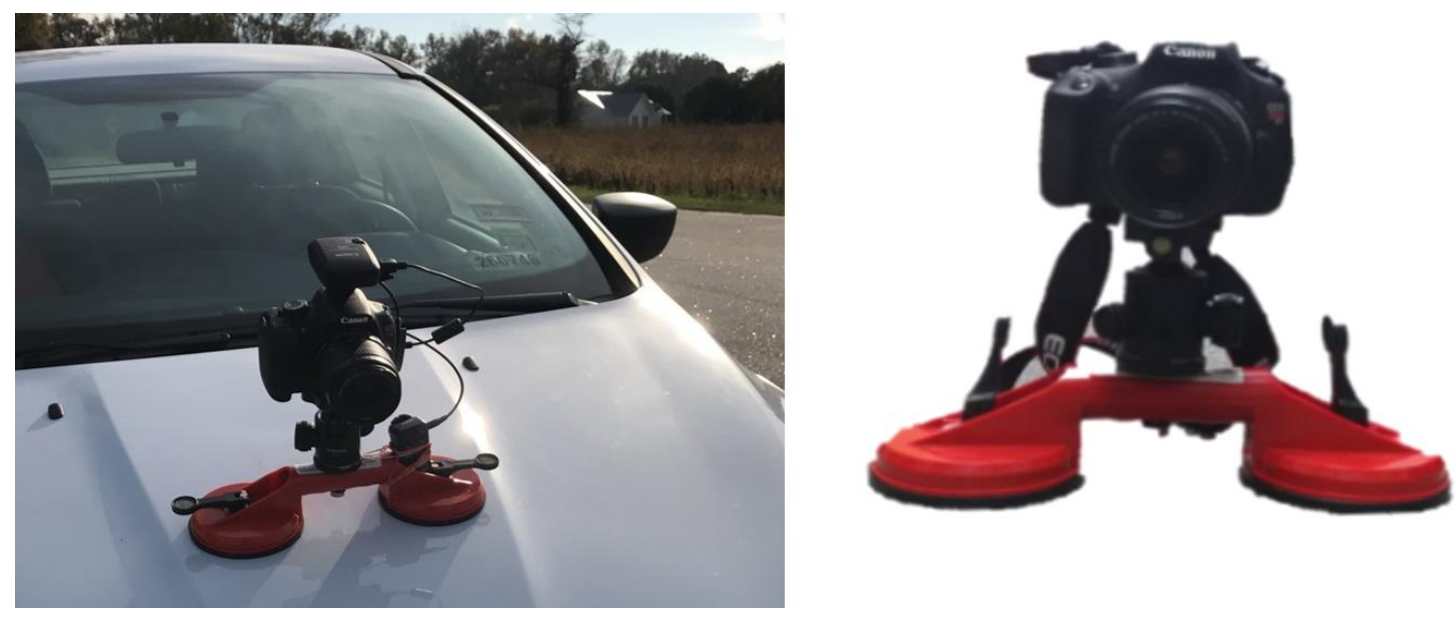

Figure 3.2 Camera with GPS unit attached mounted to hood of car.

The locations of LWST test results and photographs were used to create a database of images with the corresponding SN value before processing for analysis. The images were then reviewed and filtered. If an image was blurry or contained significant shadows that significantly reduced contrast between crack sealant and the surrounding pavement, the image and corresponding SN value were removed from the database. The number of test sites removed due to blurry images and/or improper LWST speed is shown in Table 3.1.

An algorithm was developed to calculate the percentage of the lane and wheel path within each section of LWST testing covered by crack sealant using both Adobe Photoshop ${ }^{\circledR}$ and MATLAB $^{\circledR}$. The image processing algorithm first conducts a perspective warp to convert the image to a top-down view using Photoshop ${ }^{\circledR}$. Then, the image is cropped to include only the lane of interest over the length where LWST testing was conducted. Auto-contrast, brightening tools, and a color balancing tool in Photoshop ${ }^{\circledR}$ are applied to improve the contrast between the crack sealant and the surrounding pavement. For isolated analysis of the wheel path location where the LWST test was conducted, the image is further cropped to a fixed width of 140 pixels centered around the water mark, which corresponded to approximately three wheel widths, capturing the expected range of traffic wander within the wheel path (Luo et al. 2011).

Each cropped lane width and wheel path image is then imported into MATLAB ${ }^{\circledR}$. In MATLAB $^{\circledR}$, each image is converted from color to greyscale and subsequently converted to a binary image (i.e., black and white) using adaptive thresholding. This is a built-in function in 
MATLAB ${ }^{\circledR}$ that sorts through an image and converts a color image to a binary one. The way that this process works in MATLAB ${ }^{\circledR}$ is by examining a smaller selection of the image and determining what is the foreground and background via differences in overall contrast (Puneet 2013). For the purposes of this research the background (roadway) was determined to be lighter than the crack sealant and as a result the adaptive thresholding.

An example of (a) an original photograph, (b) perspective-corrected, and (c) wheel path only and (d) final binary wheel path image is shown in Figure 3.3. The algorithm was verified using a subset of images by overlaying final binary images with the initial perspective-corrected color image to ensure that the crack sealant was properly identified and delineated from the surrounding pavement.

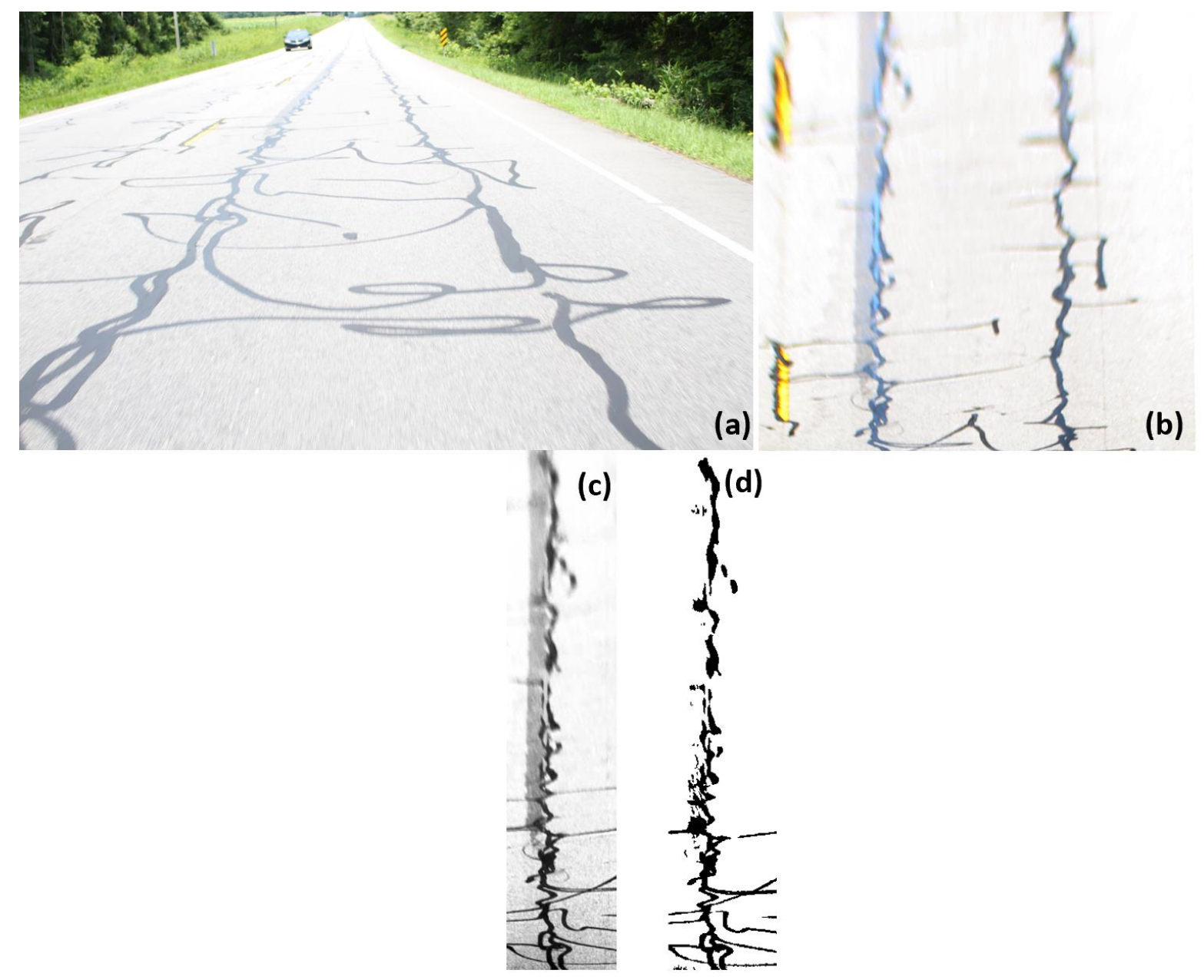

Figure 3.3 Image analysis process (a) initial image, (b) perspective fixed, (c) contrast increased and wheel path focused (d) binary image. 


\section{RESULTS}

\subsection{BASELINE SKID NUMBERS}

For each testing location, a baseline SN value was established based on the LWST results of a portion of the roadway without crack sealant. Note that the baseline pavement frictional characteristics were not found to vary appreciably along the length of a given testing location. The baseline $\mathrm{SN}$ results are shown in Table 4.1. The baseline SN values for Locations A, B, D, E and $\mathrm{F}$ were similar and indicate that the existing pavements had good skid resistance prior to the application of crack sealing. Locations $\mathrm{C} 1$ and $\mathrm{C} 2$ has a significantly lower baseline SN value, close to the widely accepted SN threshold for high volume roads of 35 (Jayawickrama et al. 1996).

The baseline SN value was identified by selecting sections that had no sealant applied and an average of those skid numbers was calculated. In cases where there was only a single section with no sealant, only a single value could be used to establish a baseline. In other cases a representative value was used by looking at all results and calculating an average. A plot between baseline SN and PCR was determined to have no relationship. It is expected that a pavement that has a lower mean profile depth would likely have a lower baseline value due to having a smoother surface. Mean profile depth can be influenced by the size of aggregate material used in making the pavement as well as the volumetric properties of the asphalt. Pavement distresses that could have an influence on baseline skid number could be raveling and

polishing. However, these distresses were not reported for these sections. Other distresses have marginal effect on the base skid resistance. 
Table 4.1 Baseline Skid Numbers

\begin{tabular}{|c|c|}
\hline Location & Measured Baseline SN Values \\
\hline A & 49.0 \\
\hline B & 48.6 \\
\hline C1 & 37.1 \\
\hline C2 & 37.6 \\
\hline D & 44.9 \\
\hline E & 43.0 \\
\hline F & 47.1 \\
\hline
\end{tabular}

\subsection{RELATIONSHIP BETWEEN SN VALUE AND PERCENTAGE OF PAVEMENT SURFACE AREA COVERED BY CRACK SEALANT}

Once the crack sealant images had been processed and filtered, the relationship between the SN value and percentage of the pavement surface area covered by crack sealant was investigated. Figure 4.1 shows the relationship between SN values and the percentage of the total lane covered by crack sealant for each location of testing. While Location B exhibits a linear relationship between the percentage of the lane covered by crack sealant and SN, the other sections do not exhibit a clear trend. There is a significant amount of spread in the measured SN values for each testing location, with many of the reported SN values falling below generally accepted threshold values of 30 for low volume roads and 35 for high volume roads (Luo et al. 2011). Similarly, there is a wide range in the percentage of the lane covered by crack sealant along the length of each testing location; the percentages of the pavement lane covered by crack sealant exceed 40 percent in some test sites, indicating highly excessive crack sealant application. Interestingly, Location $\mathrm{C}$ exhibits the highest percentage of the pavement covered by crack sealant but did not have the worst alligator index or NCDOT rating index (see Table 3.1), which can be explained by visual observations that crack sealant was applied with a wide overband and to locations where cracks were not present within Location $\mathrm{C}$. The results indicate that the amount of crack sealant covering the lane width and $\mathrm{SN}$ are not correlated; this is not surprising because the LWST measures skid resistance in the left wheel path only. Therefore, the relationship between $\mathrm{SN}$ values and the percentage of the left wheel path area covered by crack sealant was 
investigated. It should be noted that skid resistance in the wheel path is most critical because it is where the majority of the traveling public's wheels will pass.
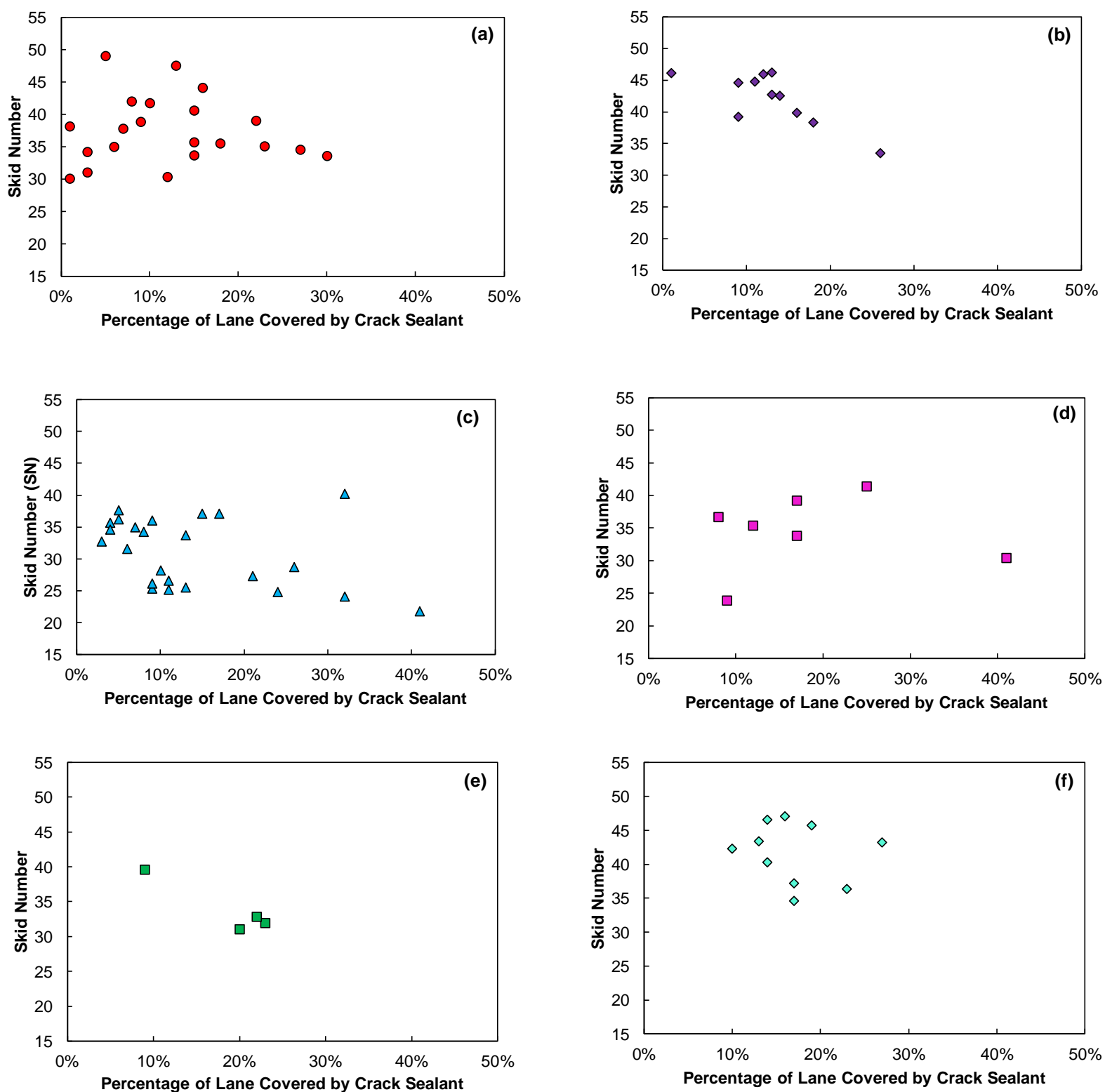

Figure 4.1 Relationship between LWST skid numbers and the percentage of the pavement lane covered by crack sealant for test sections in (a) Location A, (b) Location B, and (c) Location C (d) Location D, (e) Location E. 


\subsection{RELATIONSHIP BETWEEN SN VALUE AND PERCENTAGE OF WHEEL PATH COVERED BY CRACK SEALANT}

Figure 4.2 shows the relationship between $\mathrm{SN}$ values and the percentage of the wheel path area where LWST testing was conducted covered by crack sealant. For each location, a linear trend line was regressed to the data and the corresponding coefficients of determination $\left(\mathrm{R}^{2}\right)$ and standard error (SE) values for each location are reported in Figure 4.2. While there is some scatter in the results, the moderately high $\mathrm{R}^{2}$ values and low standard error values indicate that SN value is correlated to the percentage of the wheel path area covered by crack sealant. The trends in Figure 4.2 demonstrate that SN values generally decrease as the percentage of the wheel path covered by crack sealant increases for each testing location. These results support the hypothesis that the application of excessive crack sealant can pose a safety hazard. The primary distresses that generally occur in the wheel path are longitudinal cracking and alligator cracking, which makes it is more likely that sealant will be applied in the wheel path. In addition to posing skid loss, pavements with alligator and longitudinal cracking area generally poor candidates for crack sealing because these distresses indicate an underlying structural problem in the pavement. Crack sealing does not increase the structural capacity of a pavement. 

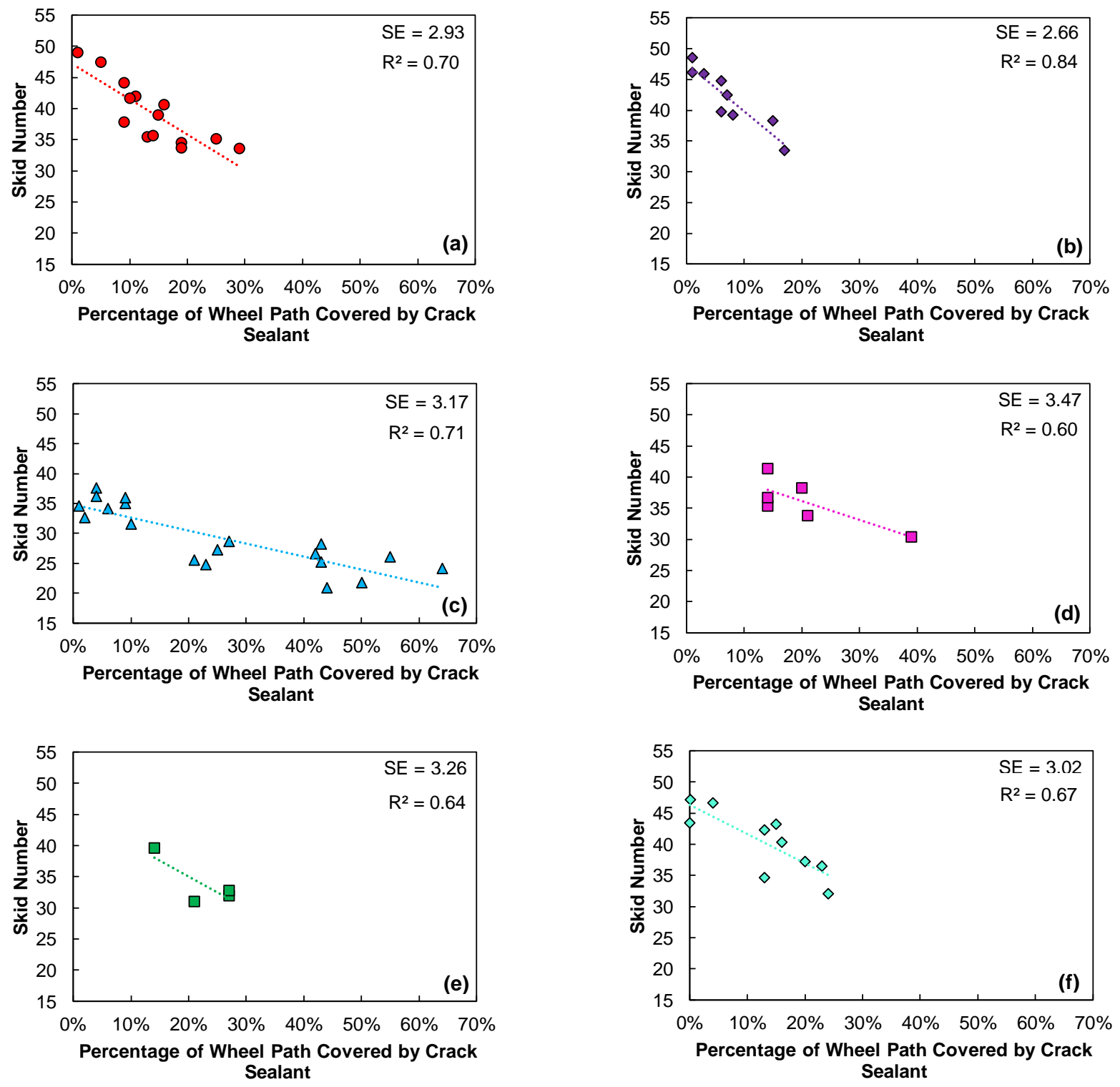

Figure 4.2 Relationship between LWST skid numbers and the percentage of the wheel path covered by crack sealant for test sections in (a) Location A, (b) Location B, (c) Location C, (d) Location D, (e) Location E and (f) Location F.

Once it was established that the amount of crack sealant in the wheel path affects skid resistance, efforts were made to unify the results of the different testing locations. Figure 4.3 shows the relationship between $\mathrm{SN}$ and the percentage of the wheel path covered by crack sealant for all testing locations. The results demonstrate that the baseline skid resistance of the pavement affects the relationship between SN and the percentage of the wheel path covered by crack 
sealant. Locations A, B, D, E, and F all have good baseline conditions (see Table 4.1) and the results of both data sets follow a similar trend in Figure 4.3. Both sections C1 and C2 had a significantly lower baseline $\mathrm{SN}$ value, and it can be seen that the Location $\mathrm{C}$ results generally fall below Locations A, B, D, E, and F in Figure 4.3.

No discernable trend in the relationship between the SN value and the percentage of the wheel path covered in crack sealant for baseline skid values ranging from 43 to 49. As seen above in Figure 4.2, each location displays a different slope of SN vs. percentage of wheel path covered in crack sealant. Location $\mathrm{C}$ exhibits a significantly lower slope than the other sections. This is attributed to its significantly lower baseline skid value. For the other sections, there is no clear trend in slope with baseline skid values.

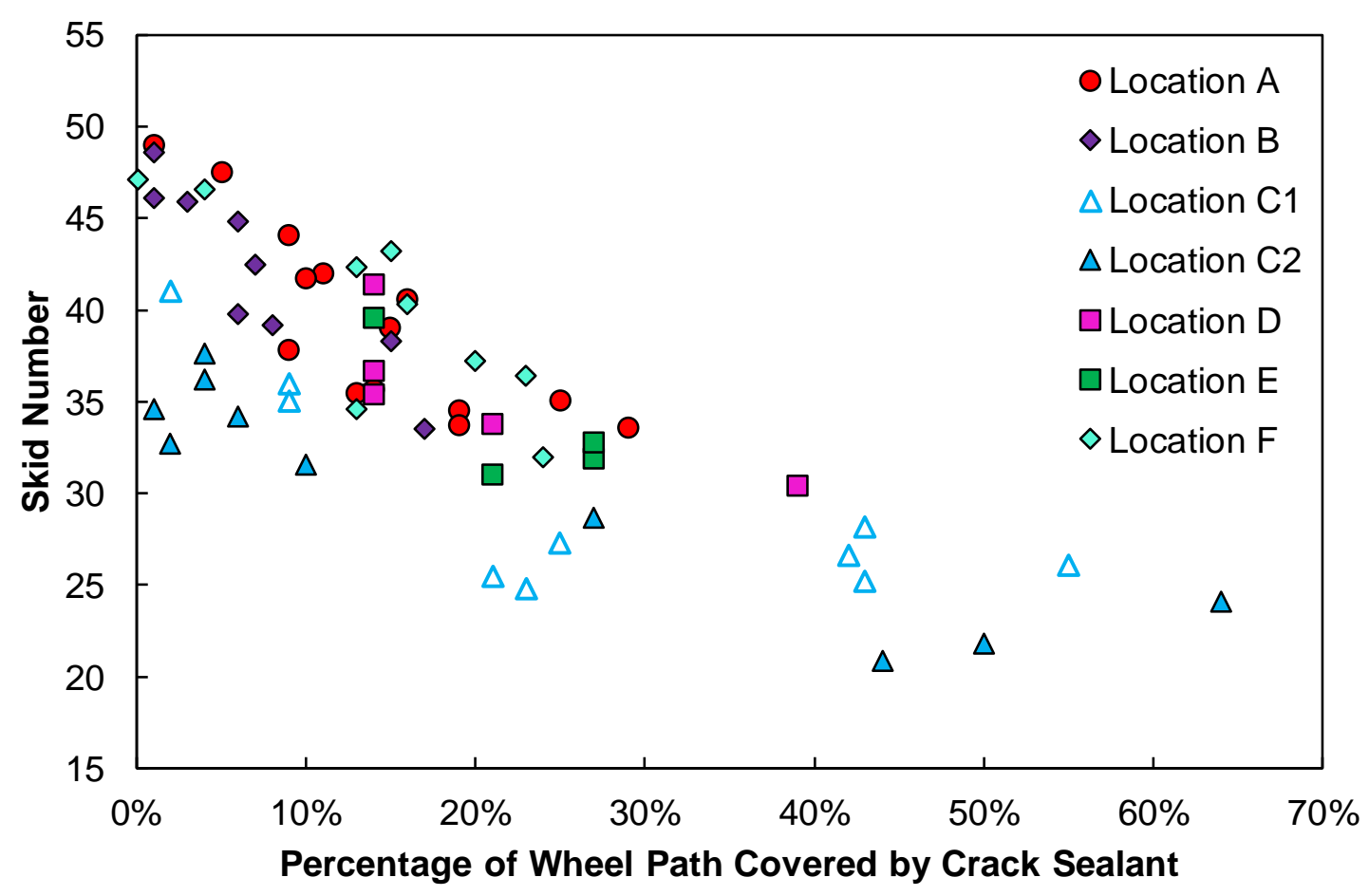

Figure 4.3 Relationship between LWST skid numbers and the percentage of the wheel path covered by crack sealant for all test sections.

In a further effort to unify the results of the different testing locations, the difference between the baseline $\mathrm{SN}$ and the $\mathrm{SN}$ value measured at each test site with crack sealant present was investigated, referred to as the change in $\mathrm{SN}$ herein. Figure 4.4 shows the relationship between 
the change in SN and the percentage of the wheel path covered by crack sealant for each testing location. While there is significant scatter in the results, all locations exhibit an overall positive trend, indicating that higher amounts of crack sealant application in the wheel path generally correspond to greater loss in skid resistance. The slope of the relationship between the change in $\mathrm{SN}$ and the percentage of the wheel path covered by crack sealant is significantly lower for Location $\mathrm{C}$ than the other testing locations, indicating the change in $\mathrm{SN}$ due to crack sealant application is also affected by the baseline pavement skid resistance. In addition, the slopes of the individual plots for Locations A, B, D, and E differ somewhat. However, when the results are combined, as shown in Figure 4.5, it can be seen that the results of the different sections are generally in agreement. Due to the differing slopes but overall similar trend, the categorical approach was used, which grouped pavements into good condition (43<) and poor condition (<38). Analysis of additional sections with a baseline value ranging from 38-43 could help inform the trend of baseline skid resistance in future work. 

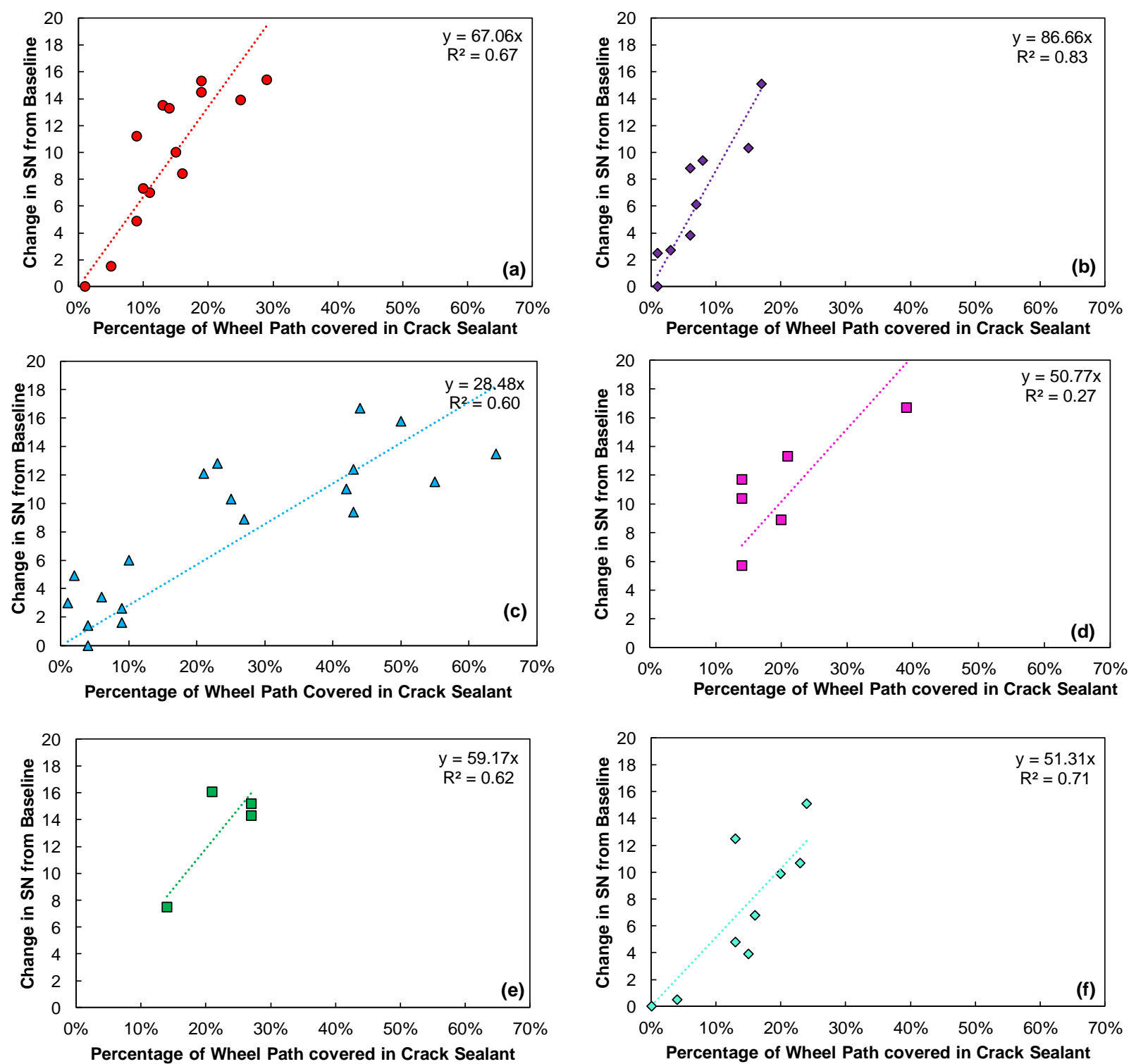

Figure 4.4 Relationship between the change in skid numbers from the baseline and the percentage of the wheel path covered by crack sealant for test sections in (a) Location A, (b) Location B, and (c) Location C (d) Location D (e) Location E (f) Location F. 


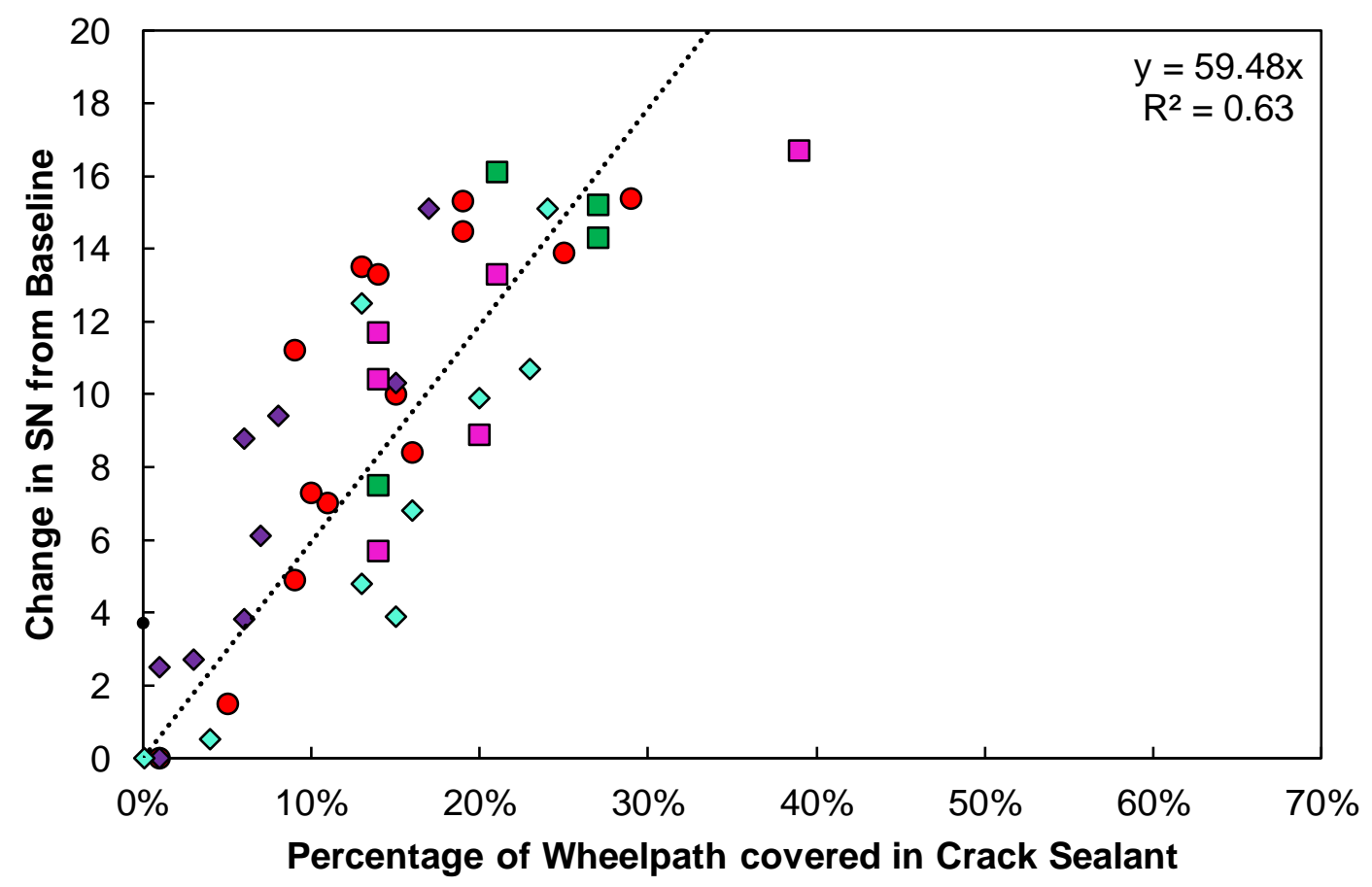

Figure 4.5 Combined relationship between change in skid numbers from the baseline and the percentage of the wheel path covered by crack sealant for test sections A, B, D, E, and F. The combined results of the change in SN versus the percentage of wheel path covered by crack sealing for all locations are shown in Figure 4.6. The results of Location $C$ fall towards the lower bound of the scatter of the results for the other test sections for relatively low crack sealant wheel path coverages and deviate from the trends of the other sections at relatively high percentages of crack sealant coverage in the wheel path. However, the data corresponding to Location C extend to higher crack sealant coverages than the other sections so definitive trends are difficult to ascertain. 


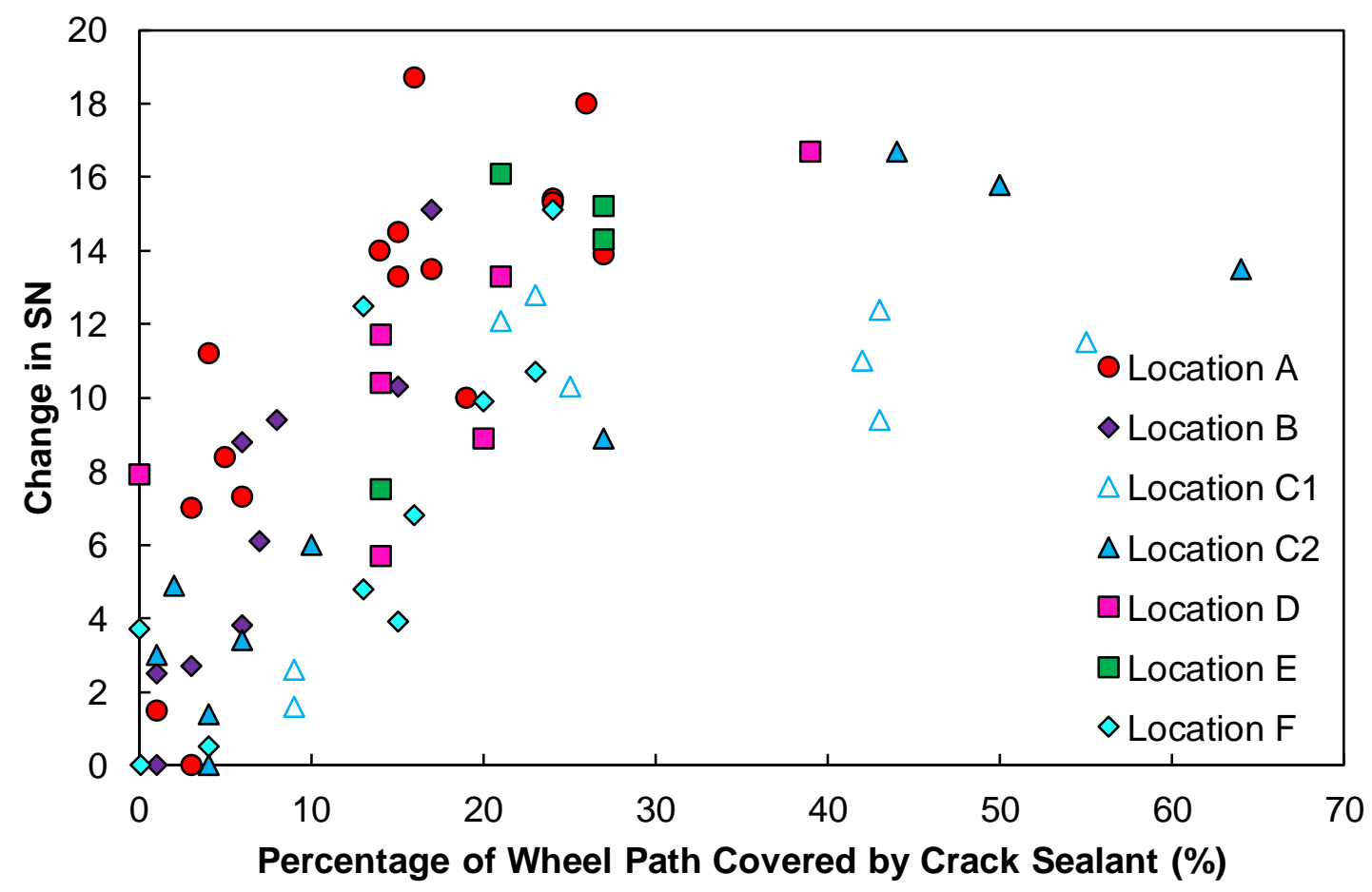

Figure 4.6 Relationship between the change in skid numbers from the baseline and the percentage of the wheel path covered by crack sealant for all test sections.

\subsection{ESTABLISHMENT OF PAVEMENT CONDITIONS WHERE CRACK SEALING MAY POSE SAFETY HAZARD}

The sensitivity of the relationship between $\mathrm{SN}$ and the percentage of the wheel path covered by crack sealant to the existing pavement SN suggests that the pavement conditions for which sealing will pose a safety hazard depend on the existing pavement skid resistance. Roadways with relatively high amounts of cracking and good baseline skid resistance may be crack sealed without risking a skid resistance safety hazard compared to roadways with poor baseline skid resistance. Therefore, maximum percentages of the wheel path that can be covered by crack sealant without posing safety hazards were defined as a function of the existing pavement SN value. The established limits were then related to the pavement distress survey results to define pavement conditions where sealing should be avoided. It should be noted that the effect of crack sealant configuration could impact the established limits based on pavement distress survey results; however, the effect of crack sealant configuration on skid resistance could not be evaluated in this study because all test sections evaluated included the overband configuration. 
The overband configuration leads to greatest surface coverage and thus, the established thresholds can be regarded as conservative for other configuration types.

\subsubsection{ALLOWABLE PERCENTAGE OF CRACK SEALANT IN WHEEL PATH}

To establish guidance on the allowable percentages of crack sealant application in the wheel path, the results of Locations A, B, D, E, and F were analyzed together given their good baseline $\mathrm{SN}$ values (i.e., 43 and above), while Locations $\mathrm{C} 1$ and $\mathrm{C} 2$ were analyzed separately due to their relatively poor baseline $\mathrm{SN}$ values (i.e., 37). Linear regression of the relationship between SN value and the percentage of the wheel path covered by crack sealant was conducted. Based on the regression results, the 90 percent confidence intervals were established using the upper and lower bounds defined by Equation (4-1).

$$
\text { Bound }=\hat{y} \pm S E \cdot t_{c r i t}
$$

Where $\hat{y}$ is the $\mathrm{SN}$ value predicted by the regression line, $S E$ is the standard error of the regression line, and $t_{\text {crit }}$ is the critical value on the $t$ distribution for the desired confidence level. To define the confidence interval bounds, the $\alpha$ value used to determine $t_{\text {crit }}$ was 0.05 , meaning that there is a 5 percent probability of a value falling below the lower bound and 5 percent probability of a value falling 5 percent above the upper bound. Given the sample sizes, the $t_{\text {crit }}$ value for Location C is 2.093 and the $t_{c r i t}$ value for the combined results of Locations A, B, D, E, and $\mathrm{F}$ is 1.684. The results are shown in Figure 4.7. 

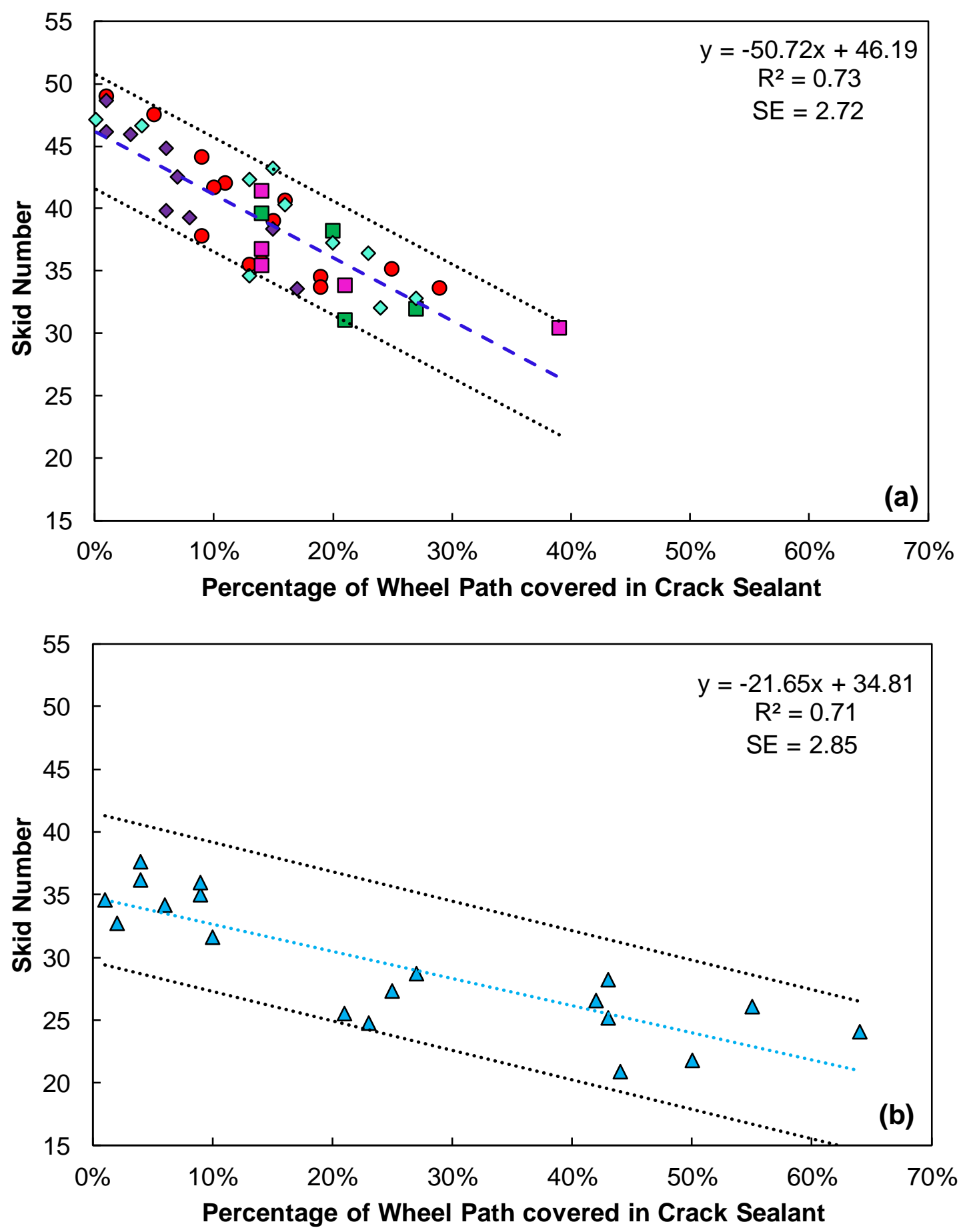

Figure 4.7 Relationship between LWST skid number and the percentage of the wheel path covered by crack sealant with 95 percent confidence intervals (dotted lines) for (a) Locations A, B, D, E, and F, and (b) Location C. 
The linear regression model and confidence intervals were used to establish limits for the percentage of the wheel path that can be covered by crack sealant without dropping below SN thresholds of 30 and 35 . A SN threshold of 30 is often applied to low-volume roadways whereas a SN threshold of 35 is often applied to high-volume roadways (Jayawickrama et al. 1996). When establishing these limits, two reliabilities were considered: 50 percent and 95 percent. To establish these thresholds, a similar approach to the reliability concept implemented in Pavement ME was used (ARA Inc. 2003). The 50 percent reliability threshold corresponds to the Figure 4.7 regression model predictions. The 95 percent reliability threshold corresponds to the lower confidence interval bounds in Figure 4.7; that is, there is 95 percent confidence that the established limit for crack sealant coverage will not lead to an SN value lower than the critical safety threshold.

Table 4.2 shows the established limits for acceptable crack sealant application in the wheel path. It can be seen that the allowable amount of crack sealant in the wheel path is significantly higher for (a) the good baseline condition (minimum SN value of 43) than the (b) poor baseline condition (SN value of 37). These results indicate that the existing condition of the roadway plays a significant role in establishing whether crack sealant can be applied without reaching an unsafe condition. The relatively high limits for allowable amounts of crack sealant in the wheel path for Locations A, B, D, E, and F suggest that many pavements are good candidates for crack sealing without posing a safety hazard. Figure 4.8 provides examples of pavement sections exhibiting 17 percent and 27 percent crack sealant coverage in the wheel path to provide some context to these thresholds given in

\section{Table 4.2.}

The results of Locations C1 and C2 imply that crack sealing may be an inappropriate preventive maintenance strategy for pavements with deteriorated baseline SN approaching safety limits (i.e., 37) because even small amounts of crack sealant in the wheel path can lead to a drop in skid resistance that could pose a safety hazard to traffic. For high volume roadways where the SN value should not drop below 35, sealing should be avoided. For low volume roadways, crack sealing may be possible without leading to conditions dropping below the commonly accepted $\mathrm{SN}$ threshold of 30 if relatively minor wheel path cracking exists such as that shown in Figure 
4.8 (a). However, it is generally recommended that crack sealing be avoided in conditions where the existing pavement has marginal skid resistance and that an alternative preventive maintenance strategy be sought that would increase frictional characteristics (e.g., chip seal, microsurfacing).

Table 4.2 Thresholds for Allowable Percentages of Crack Sealant in the Wheel Path to Maintain Safe Conditions.

\begin{tabular}{|c|c|c|c|}
\hline \multirow{2}{*}{$\begin{array}{c}\text { Existing Skid } \\
\text { Resistance }\end{array}$} & \multirow{2}{*}{$\begin{array}{c}\text { SN } \\
\text { Threshold }\end{array}$} & \multicolumn{2}{|c|}{$\begin{array}{c}\text { Threshold for Percentage of Wheel } \\
\text { Path Covered by Crack Sealant (\%) }\end{array}$} \\
\cline { 3 - 4 } & & $\mathbf{5 0 \%}$ Reliability & $\mathbf{9 5 \% \text { Reliability }}$ \\
\hline $\begin{array}{c}\text { Good Condition } \\
(\geq 43)\end{array}$ & 35 & 22 & 17 \\
\cline { 2 - 4 } & 30 & 32 & 27 \\
\hline $\begin{array}{c}\text { Deteriorated Condition } \\
(37)\end{array}$ & 35 & 3 & 18 \\
\cline { 2 - 4 } & 30 & 24 & \\
\hline
\end{tabular}
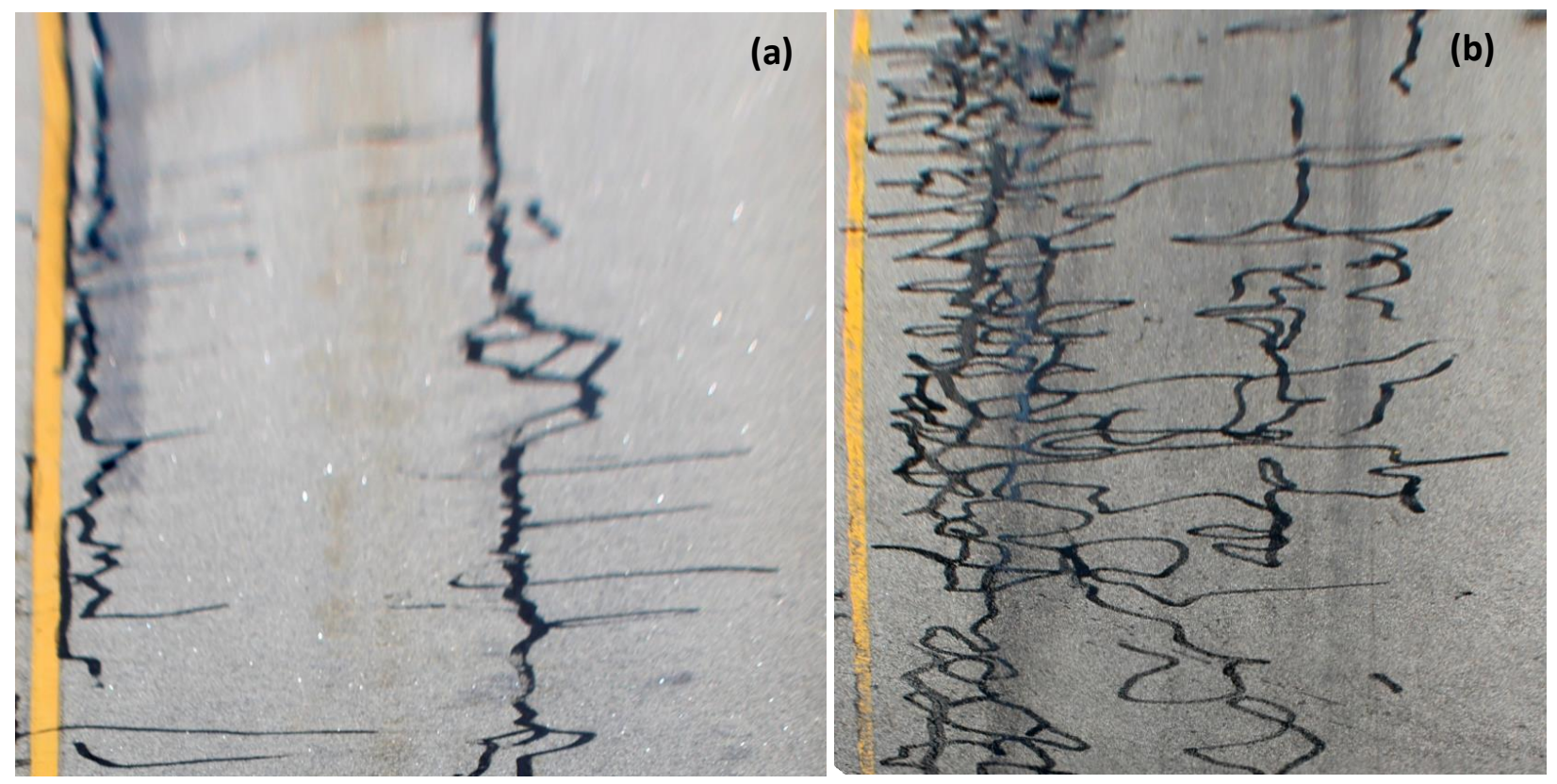

Figure 4.8 Visual representation of (a) 17 percent crack sealant within the wheel path and (b) 27 percent crack sealant coverage within the left wheel path.

\subsubsection{ALLOWABLE PAVEMENT DISTRESS CONDITIONS}

The pertinent information about the different sections was compiled to examine the effects of the existing pavement condition on the amount of crack sealant applied and corresponding skid 
resistance. The compiled information is presented in Table 4.3. The maximum and average values reported in the table refer to the maximum and average values for a given location of testing, respectively. The results presented demonstrate that the crack sealant coverage varies considerably along the different locations of testing; therefore, it is expected that the pre-existing pavement condition also varied within each location of testing. However, pavement distress survey results of the pre-existing pavement are reported as a single value for each segment indicated in Table 4.3. Therefore, the worst safety conditions for a given location, in terms of skid number and crack sealant coverage in the wheel path, were compared to the pavement distress survey data to establish pavement conditions where crack sealant application should be avoided. To ensure that this approach was valid, the max crack sealant coverage in the wheel pat and minimum skid numbers of the different locations were correlated as shown in Figure 4.9; the results indicate the two values are highly correlated and thus, demonstrate the validity in using the maximum crack sealant coverage in the analysis. It can be observed that both Location $\mathrm{C} 1$ and $\mathrm{C} 2$ are not outliers in this relationship, unlike with max percentage vs. alligator index. This is likely due to the fact that alligator index is a single measurement for a relatively large section which could mean that the alligator index represents a small section of the pavement section and may not account for the worst section available.

Table 4.3 Summary of Crack Sealant Coverage, SN Values, and Pre-existing Condition of Locations Evaluated.

\begin{tabular}{|c|c|c|c|c|c|c|c|}
\hline Location & A & B & C1 & C2 & D & E & F \\
\hline $\begin{array}{c}\text { Maximum Crack Sealant } \\
\text { Coverage in the Wheel Path }\end{array}$ & $29 \%$ & $17 \%$ & $55 \%$ & $64 \%$ & $39 \%$ & $27 \%$ & $27 \%$ \\
\hline $\begin{array}{c}\text { Average Crack Sealant } \\
\text { Coverage in the Wheel Path }\end{array}$ & $14 \%$ & $11 \%$ & $27 \%$ & $21 \%$ & $20 \%$ & $22 \%$ & $16 \%$ \\
\hline Minimum SN & 30.10 & 33.50 & 24.80 & 20.9 & 30.40 & 31.00 & 32.80 \\
\hline Average SN & 37.49 & 42.68 & 29.57 & 30.24 & 36.15 & 33.83 & 44.16 \\
\hline Alligator Cracking Index & 86.80 & 76.80 & 71.19 & 76.44 & 64.44 & 72.63 & 76.40 \\
\hline Oxidation Rating & 0 & 0 & 100 & 100 & 0 & 0 & 0 \\
\hline Transverse Cracking Index & 80 & 80 & 80 & 80 & 80 & 80 & 100 \\
\hline
\end{tabular}




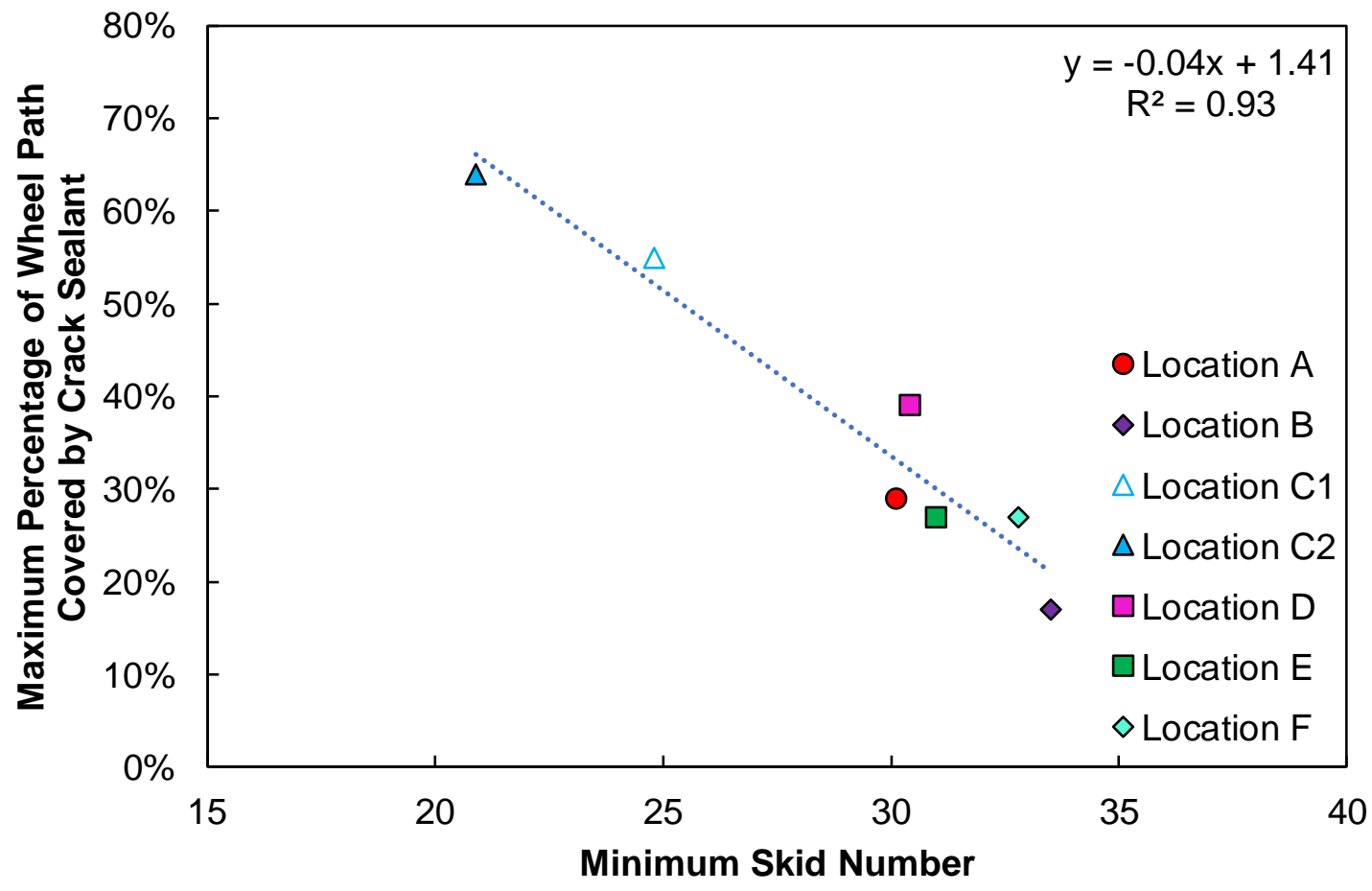

Figure 4.9 Relationship between location minimum skid number and max crack sealant coverage in the wheel path.

Table 4.3 demonstrates that the sections evaluated were relatively similar in terms of transverse cracking; furthermore, transverse cracking is anticipated to have only a marginal effect on skid resistance in the wheel path compared to alligator cracking. Because transverse cracks are perpendicular to the flow of traffic, sealant application is expected to have a minimal impact on overall skid resistance. In contrast, the sealing of alligator cracks leads to a high concentration of crack sealant in the wheel path. Location $\mathrm{C}$ is the only roadway that did not exhibit evidence of severe oxidation; it is interestingly also the pavement with the worst baseline $\mathrm{SN}$ value and highest amount of crack sealant coverage in the wheel path. Furthermore, the results of Location F compared to the other locations indicate transverse cracking did not lead to excessive crack sealant application; while Location F shows the greatest transverse cracking, it does not show nearly the highest crack sealant coverage in the wheel path. Therefore, pavement conditions where crack sealing should be avoided due to the risk of posing a safety hazard were developed based on relationship between alligator cracking index, which includes the combined effects of 
low, moderate, and high severity alligator cracking, and maximum crack sealant coverage in the wheel path.

The relationship between the alligator cracking index and maximum crack sealant coverage in the wheel path is shown in Figure 4.10. It can be seen that a moderate relationship between maximum crack sealant coverage and alligator cracking index exists, with the exception of Location $\mathrm{C}$ which shows outlier behavior. Location $\mathrm{C}$ was omitted from the analysis to establish was created to establish thresholds for acceptable alligator cracking indices for sealing because the low baseline SN value prohibits safe application of sealant, as previously discussed. The scatter in the relationship between maximum crack sealant coverage in the wheel path and alligator cracking index is not unexpected because each section exhibited a wide range of values of the percentage of the wheel path covered by crack sealant but only a single alligator index is given for the entire section. Thus, the exact location of alligator index measurement may not align with that of the maximum sealant coverage. A linear trend line was fit to the relationship between alligator cracking index and maximum sealant coverage in the wheel path for all other locations. The trend line was used to establish alligator cracking index thresholds to maintain SN values of 35 and 30 using the 95 percent reliability thresholds for crack sealant coverage in the wheel path given in

Table 4.2 to ensure that the established thresholds are conservative. The corresponding alligator index thresholds are shown in Table 4.4. Note that the established thresholds pertain to pavements with good baseline skid resistance (i.e., $\mathrm{SN} \geq 43$ ). It is recommended that the established threshold be strengthened in the future by incorporating a larger database of locations. 


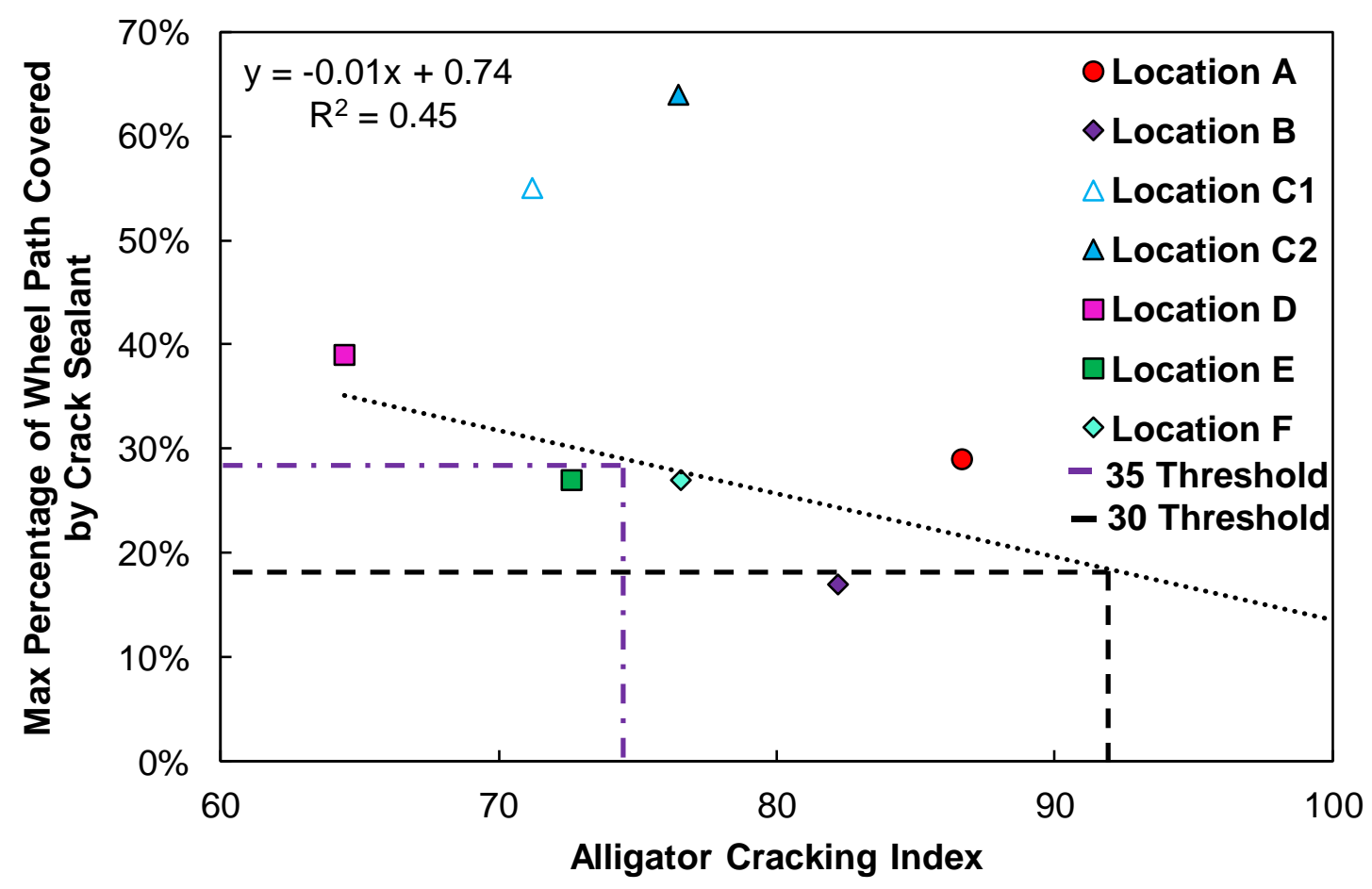

Figure 4.10 Relationship between alligator cracking index and maximum percentage of wheel path covered by crack sealant.

Table 4.4 Alligator Cracking Index Thresholds to Mitigate Skid Hazard for Pavements with Good Baseline Skid Resistance ( $\mathrm{SN} \geq 43$ ).

\begin{tabular}{|c|c|}
\hline $\begin{array}{c}\text { SN } \\
\text { Threshold }\end{array}$ & $\begin{array}{c}\text { Alligator Index } \\
\text { Threshold }\end{array}$ \\
\hline 35 & 92 \\
\hline 30 & 75 \\
\hline
\end{tabular}




\section{CONCLUSIONS AND RECOMMENDATIONS}

The following conclusions and recommendations are drawn from the results of this study:

1. An increase in the percentage of the wheel path covered by the crack sealant generally leads to a decrease in pavement skid resistance.

2. The effect of crack sealant in the wheel path on skid resistance is a function of the existing pavement's frictional characteristics. Pavements with deteriorated frictional characteristics may be poor candidates for crack sealing due to safety concerns.

Pavements where crack sealing will be an effective preventive maintenance treatment (i.e., low to moderate cracking) and have good skid resistance can generally be safely be sealed.

3. The concentration of crack sealant in the wheel path is influenced by the alligator cracking extent and severity of the pavement. Therefore, future crack sealant specifications should include alligator cracking condition thresholds for crack sealant project selection to avoid safety hazards.

4. All sections evaluated in this project included the overband crack sealant configuration. The effects of other types of crack sealant configurations on pavement skid resistance merits consideration in future work.

5. The pavements evaluated in this study had either skid numbers greater than or equal to 43 or 37. Additional sections with baseline skid numbers in the range of 37 to 43 should be investigated in future work to better elucidate the safety of crack sealant application on pavements with acceptable but relatively low skid resistance. 


\section{REFERENCES}

1. Al-Qadi, I.L., J.-F. Masson, S.-H. Yang, E.H. Fini, and K.K. McGhee. Development of Performance-Based Guidelines for Selection of Bituminous-Based Hit-Poured Pavement Crack Sealant: An Executive Summary Report. VTRC 09-CR7. Virginia Transportation Research Council, Richmond, 2009, pp. 3-26.

2. American Society for Testing and Materials. Standard Test Method for Skid Resistance of Paved Surfaces Using a Full-Scale Tire, ASTM E274, West Conshocken, PA, 2011

3. ARA Inc. Guide for Mechanistic-Empirical Design of New and Rehabilitated Pavement Structures Appendix BB: Design Reliability, National Cooperative Highway Research Program, National Research Council, Washington, D.C., 2003

4. California Department of Transportation. Chapter 3 Crack Sealing and Filling. Caltrans Flexible Pavement Materials Program, California, 2003

5. Chehovits, J., M. Manning. Materials and Methods for Sealing Cracks in Asphalt Concrete Pavements. Transportation Research Record, Washington, D.C., 1984.

6. Decker, D. S. Best Practices for Crack Treatments for Asphalt Pavements, NCHRP Report 784, National Research Council, Washington, D.C., 2014.

7. Gnatenko, R., K. Tsyrkunova, V. Zhdanyuk. Technological sides of crack sealing in asphalt pavements. Transportation Research Procedia, 2016, pp. 804-810.

8. Hand, A., K. Galal, D. Ward, C. Fang. Cost-Effectiveness of Joint and Crack Sealing: Synthesis of Practice. Journal of Transportation Engineering, 2000, pp. 521-529.

9. Jayawickrama, P. W., R. Prasanna, S.P. Senadheera. Survey of State Practicies to Control Skid Resistance on Hot-Mix Asphalt Concrete Pavements. Transportation Research Record: Journal of the Transportation Research Board, 1996, 1536, pp. 52-58.

10. Luo, W., K. Wang, L. Li. Wheel Path Definition based on A Multi-Factor Traffic Wander Model. Presented at 90th Annual Meeting of the Transportation Research Board, Washington, D.C., 2011.

11. Masson, J-F., P. Collins, M. Lowery. Temperature control of hot-poured sealants during the sealing of pavement cracks. Construction and Building Materials, 2005, pp. 423-429.

12. McCarthy, R., E. Izeppi, G. Flintsch, K. McGhee. Comparison of Locked Wheel and Continuous Friction Measurement Equipment. Transportation Research Board, Washington, D.C., 2018

13. Minnesota Department of Transportation. Special Provisions 2005. MNDOT Special Provisions SP2005BOOK, Minnesota, 2006 
14. National Guide to Sustainable Municipal Infrastructure. Guidelines for Sealing and Filling Cracks in Asphalt Concrete Pavement. Federation of Canadian Municipalities and National Research Council, March, 2003.

15. North Carolina Department of Transportation. Section 657 Seal Existing Pavement Cracks and Joints. NCDOT Specifications, North Carolina, 2012.

16. North Carolina Department of Transportation. Pavement Condition Survey Manual. NCDOT, North Carolina, 2016.

17. Stantec Consulting Ltd. (2013). Asphalt Crack Sealing Practices and Processes. Stantec Consulting, Regina, Canada, 2013

18. Truschke, C., D. Peshkin, K. Smith, K. Smith. Colorado Department of Transportation hot mix asphalt crack sealing and filling best practices guidelines. Colorado Department of Transportation, Colorado, 2014

19. Wang, H., Z. Wang. Evaluation of pavement surface friction subject to various pavement preservation treatments. Construction and Building Materials, 2013, pp. 194-202.

20. Yildirim, Y. Field performance comparison of asphalt crack filling materials: hot pour versus cold pour. Canadian Journal of Civil Engineering, 2007, pp. 505-512. 
APPENDIX 


\section{APPENDIX A: MATLAB SCRIPT}

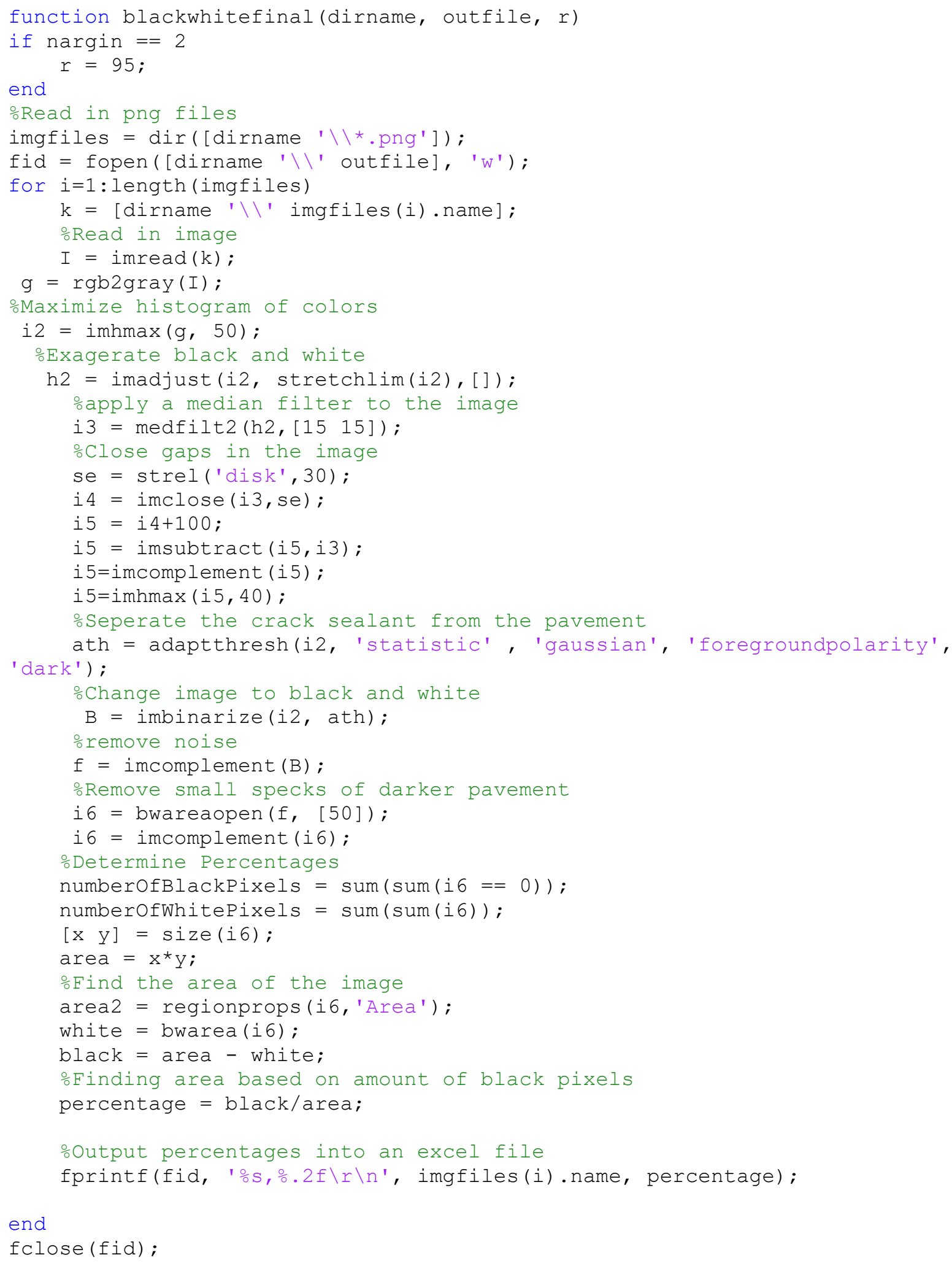

